This document is the accepted manuscript version of the following article:

Di Giovannantonio, M., \& Contini, G. (2018). Reversibility and intermediate steps as key tools for the growth of extended ordered polymers via on-surface synthesis. Journal of Physics: Condensed Matter, 30(9), 093001 (22 pp.). https://doi.org/10.1088/1361-648X/aaa8cb

\title{
Reversibility and Intermediate Steps as Key Tools for the Growth of Extended Ordered Polymers via On-Surface Synthesis
}

\author{
Marco Di Giovannantonio ${ }^{1}$ and Giorgio Contini ${ }^{2,3, *}$ \\ ${ }^{1}$ Empa - Swiss Federal Laboratories for Materials Science and Technology, Überlandstrasse 129, \\ 8600 Dübendorf, Switzerland \\ ${ }^{2}$ Istituto di Struttura della Materia, CNR, Via Fosso del Cavaliere 100, 00133 Roma, Italy \\ ${ }^{3}$ Department of Physics, University of Rome Tor Vergata, Via della Ricerca Scientifica 1, 00133 \\ Roma, Italy \\ *Corresponding author: giorgio.contini@,cnr.it \\ ORCID Marco Di Giovannantonio: https://orcid.org/0000-0001-8658-9183 \\ ORCID Giorgio Contini: https://orcid.org/0000-0002-6248-9716
}

\section{Table of Contents}

1. Introduction

2. From molecular self-assembly to surface-confined polymerization

2.1. Covalent coupling on surfaces

2.2. Ullmann coupling

2.3. Other chemical reactions

3. Challenges of surface-confined polymerization

4. Reversibility and intermediate steps as key concepts

4.1 Condensation of boronic acid derivatives

4.2 Schiff-base coupling

4.3 Exploiting intermediate states

5. Conclusions

\begin{abstract}
Surface-confined polymerization is a bottom-up strategy to create one- and two-dimensional covalent organic nanostructures with a $\pi$-conjugated backbone, which are suitable to be employed in real-life electronic devices, due to their high mechanical resistance and electronic charge transport efficiency. This strategy makes it possible to change the properties of the final nanostructures by a careful choice of the monomer architecture (i.e. of its constituent atoms and their spatial arrangement). Several chemical reactions have been proven to form low-dimensional polymers on surfaces, exploiting a variety of precursors in combination with metal (e.g. $\mathrm{Cu}, \mathrm{Ag}$,
\end{abstract}


$\mathrm{Au}$ ) and insulating (e.g. $\mathrm{NaCl}, \mathrm{CaCO}_{3}$ ) surfaces. One of the main challenges of such an approach is to obtain nanostructures with long-range order, to boost the conductance performances of these materials. Most of the exploited chemical reactions use irreversible coupling between the monomers and, as a consequence, the resulting structures often suffer from poor order and high defect density. This review focuses on the state-of-the-art surface-confined polymerization reactions, with particular attention paid to reversible coupling pathways and irreversible processes including intermediate states, which are key aspects to control to increase the order of the final nanostructure.

\section{Introduction}

Positioning matter at the nanoscale by self-organization is one of the main focuses of research on physics and chemistry of surfaces and interfaces. In the history of man, each manufactured object has been created by carefully positioning its constituents in a precise place to get the final result. In modern times things have not changed, and the request for the realization of smaller devices has pushed research toward miniaturization and control of object arranging down to the nanometer scale [1-3], reaching the target of single molecule devices [4-6]. Nanostructures based on organic materials have received great interest because of their possible application as active media in organic electronic devices and their advantages respect to the inorganic counterpart, such as for instance a cheaper production and the possibility of large scale processes. Moreover, organic materials can be deposited or grown on transparent and/or flexible substrates, allowing new application in several emerging technological fields [7-8]. The synthesis of graphene [9], a twodimensional organic sheet made of $\mathrm{sp}^{2}$-hybridized carbon atoms, and the understanding of its properties opened new perspectives in the study and application of low-dimensional organic nanomaterials. Graphene is a zero band-gap semiconductor with peculiar, yet fixed, properties [10]. It has been theoretically predicted that porous graphene has a different band-gap [11] that can be changed with the morphology and extension of the layer [12]. Moreover, the electronic structure of graphene can be modified by adsorbing molecules [13-15] or by post-synthesis modification of its structure, e.g. reducing its extension in a top-down approach by cutting it into nanoribbons using scanning tunneling microscope lithography [16].

A bottom-up strategy making use of organic building blocks that can be linked to each other forming larger superstructures is an alternative of fundamental importance in the growth of lowdimensional organic materials. The know-how of chemistry in synthesizing and handling organic molecules is transferred to the physics and chemistry of surfaces to expand the horizon of their 
applications. The use of this strategy, namely surface-confined polymerization, makes it possible to construct graphene-like systems whose architecture and electronic properties can be modified by changing the reacting molecular units [17-19]. The physical and chemical properties of the precursor molecules drive their interaction and self-organization, before being linked together to form larger systems. Exchanging or modifying the base constituents allows different structures, with diverse chemical and physical properties to be obtained. The minimization of the total energy frequently produces long-range ordered self-assembled (SA) molecular structures, increasing the intermolecular electric charge transport ability compared to isolated molecules, a crucial characteristic for the employment of these materials in electronic devices. However, SA systems are stabilized by non-covalent interactions and present poor mechanical resistance and limited electric charge transport. The interconnection between adjacent molecules via covalent bonding (i.e. forming polymers) increases their robustness and, if $\pi$-conjugated macromolecules are obtained, the electric charge can be transferred over all the polymeric backbone, making these systems more suitable than the self-assembled ones to be used as the active media in devices. While traditional solution-based synthetic chemistry typically produces disordered three-dimensional polymers, the confinement on suitable substrates can drive the growth of ordered nanostructures in two dimensions and, in some cases, allows the catalytic properties of the surface to be exploited.

Herein, several approaches using a variety of chemical reactions and involving a plethora of building blocks are reported. It is not obvious that standard synthetic routes, e.g. solution chemistry, can be successfully used on surfaces. Under certain conditions chemical reactions on surfaces can be enabled, and a new class of one- or two-dimensional (1D, 2D) organic materials can be synthesized. The creation of long-range order is not straightforward when covalent bonds are formed, and the advantages of the self-healing of defects in the molecular structure, typically gained for self-assembled monolayers (SAMs), may be lost when polymerization occurs. However, some reaction pathways are reversible under specific conditions, merging the robustness of covalently linked networks with the long-range order typical of SAMs. In addition, some reactions possess intermediate steps that can be efficiently controlled to improve the quality of the final polymeric layer. This review reports the main results concerning surface-confined reactivity, summarizing the understanding of this field in between physics and chemistry. Special attention is given to reversible reaction pathways and to irreversible reactions involving intermediate steps, as key ingredients leading to the creation of long-range ordered covalent organic networks. 


\section{From molecular self-assembly to surface-confined polymerization}

To confine the growth of molecular nanostructures in two dimensions, a suitable substrate can be used to support the growth and, sometimes, to template or catalyze the synthesis. The use of selfassembly is one of the most exploited methods to obtain surface-confined supramolecular architectures from small molecular units. The term self-assembly is widely employed in the field of supramolecular chemistry, defined as the "chemistry beyond the molecule" [20-21], allowing supramolecular architectures to be obtained, i.e. ordered structures made of molecules adsorbed on a substrate, composed of elementary units which interact with each other through non-covalent bonds. The order gained through self-organization processes often represents a desired starting point to covalently link these units together, as we will discuss below.

Ordered SAMs have been obtained by depositing a variety of molecules on several surfaces (including metals, semiconductors and insulators) and identifying the main parameters leading to the final molecular superstructure. A plethora of conformational moieties has been identified and studied in different conditions (solid-vacuum, solid-air and solid-liquid interfaces), unveiling the details of the assembly [22-41]. The subtle balance between intermolecular and molecule-surface interactions governs molecular self-assembly on surfaces which can be controlled by changing the molecules (composition and geometry), the substrate, the chirality, and external factors, such as temperature and $\mathrm{pH}$.

This has been demonstrated in several cases, as for guanine, one of the bases constituting the DNA, deposited in ultrahigh vacuum (UHV) conditions on $\mathrm{Au}(111)$ (Figure 1a). While the substrate serves to accommodate the molecules in a planar geometry, H-bonds are responsible for the selforganization in quartets, similar to what is observed in some structures of the DNA chains. Increasing the temperature, a different assembly is observed, composed of antiparallel molecular ribbons, resembling the motifs observed for guanosine derivatives in solution [42]. This balance can be tuned by the appropriate choice of substrate material and symmetry, as in the case of 4-(trans-2(pyrid-4-yl-vinyl))benzoic acid deposited on different metal substrates $(\operatorname{Pd}(110), \mathrm{Cu}(111)$ and $\operatorname{Ag}(111)$ ) to vary the surface potential experienced by the molecules [43]. On the other hand, the same self-assembled structure is observed for trimesic acid on highly oriented pyrolytic graphite (HOPG) and graphene-covered copper foil, demonstrating that in this case intermolecular interactions are dominant over the molecule-substrate interaction in stabilizing the system [44]. The 
interplay between supramolecular interactions and substrate symmetry has also been observed to drive the molecular dehydrogenation processes [45].

The composition of molecular units affect their assembly and can be used as control parameter to obtain different moieties, as has been shown for various tetrathiafulvalene derivatives at the interface between non-volatile organic solutions and the graphite. The number, length and composition of side-chains produces differently packed self-assembled structures [46]. $\mathrm{Au}(111)$ supported supramolecular structures have been realized by rationally controlling their size and aggregation pattern by tuning the non-covalent interactions between the absorbed molecules. This has been done by changing the number and position of the cyanophenyl substituents in porphyrinbased molecules. Each observed structure corresponds in a predictable fashion to the geometric and chemical nature of the porphyrin substituents (Figure 1b) [47].

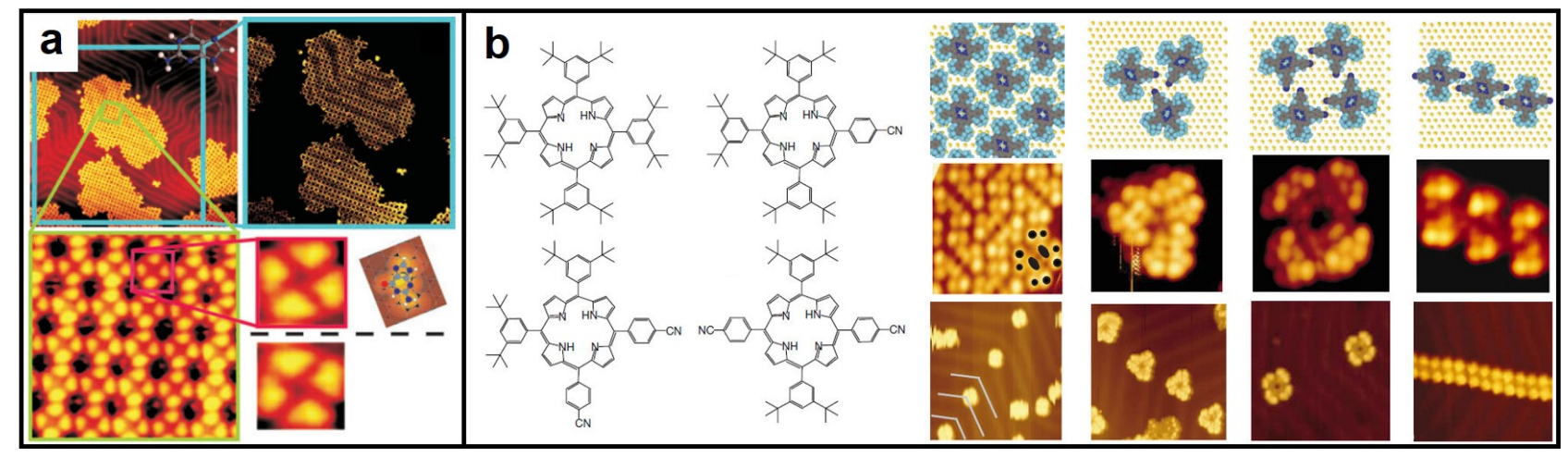

Figure 1. a: STM images reporting the self-assembled structure of guanine on Au(111) stabilized by H-bonds. Higher magnification reveals the chiral assembly of the molecules [42]. Adapted with permission from John Wiley and Sons, copyright 2005. b: Different assemblies of porphyrin-based molecules depending on the number and position of cyanophenyl substituents [47]. Adapted with permission from Nature Publishing Group, copyright 2001.

Among the studies of self-assembly on surfaces, the aspect of chirality has also received increased attention, mainly because of its importance in enantioselective heterogeneous catalysis [48-55]. The use of chiral and prochiral molecules changes the properties of the self-assembled molecular superstructure, both for aggregates and monolayers. Prochiral molecules or racemic mixtures of chiral molecules both create enantiomeric structures, generating a racemic crystal or conglomerate due to a competition between homochiral and heterochiral lateral interactions; a chiral bias can produce the disappearance of one enantiomeric structure. A small number of homochiral molecules can cause the homochirality on the entire surface. This kind of chiral amplification was coined the "sergeants-and-soldiers" principle, because few units (chiral side chain sergeants) rule the global outcome (single helicity) by cooperatively influencing the sense of helicity of the turns (soldiers) in 
the entire chain [56]. Similar behavior was found for small enantiomeric excess in the racemic mixture and named "majority rule" [57-58].

In liquid solution, solvent-induced polymorphism shows how a molecule can self-assemble in different geometries depending on several parameters, e.g. the chain length of the solvent molecules [59]. Polymorphism has also been observed for terthienobenzenetricarboxylic acid, a prochiral molecule studied on HOPG immersed in heptanoic acid. A densely packed 2D geometry is produced for concentrated solutions, in contrast with the chicken wire hexagonal moiety. The prochiral nature of the molecule leads to the formation of adsorbed structures with two morphologically different appearances in the scanning tunneling microscopy (STM) images. Random intermixing of the two enantiomers is observed for the chicken wire assembly, while the enhanced molecule-molecule interaction leads to enantiomerically pure domains in the case of densely packed geometry [60]. In the case of bicomponent systems, the final geometry of the selfassembled structure can be controlled by the surface density and molecular ratio, which are functions of the solution concentration and the surface potential, as shown for melamine and melem in aqueous solution on $\mathrm{Au}(111)$ [61]. Bicomponent 1D and 2D networks stabilized via H-bonds have been studied at the solid-liquid interface with particular attention being paid to polymorphism and phase segregation, by changing one of the two precursors or the solution concentration. A priori control of the energetic contributions in crystallization, polymorphism, and phase segregation can improve the molecular engineering providing reliable design protocols for the precise and tunable nanopatterning of surfaces [62].

All the examples present in literature concerning self-assembled structures on surfaces demonstrate how supramolecular chemistry leads to the construction of complex and functional chemical systems from elementary components held together by non-covalent intermolecular forces. This is possible due to molecular recognition, characterized by selective processes based on the information stored in each interacting species [63]. Self-organization of supramolecular entities takes place through progressive build-up of the final products, exploring all the available structure/energy combinations in a reversible fashion. Thus, self-organization processes are in principle able to select the correct molecular components for the generation of a given supramolecular entity from a collection of building blocks. This selection takes place by virtue of the dynamic character of supramolecular chemistry, leading to the concept of Constitutional Dynamic Chemistry (CDC), theorized by Jean Marie Lehn [64]. CDC operates at both molecular and supramolecular levels: in the first case, it involves the exchange of functional groups within a molecule, being chemically dynamic. In the second case, it is responsible for the exchange of molecular units in the self-assembled structure, being physically dynamic. In both cases a 
continuous change in the constitution, concerning the nature, number and arrangement of the components of molecular or supramolecular entities, takes place through dissociation into various components and re-association into the same entity or into different ones [63,65]. The reversibility of molecular interaction is therefore the key aspect for the dynamic character that is crucial when synthesizing covalently-linked networks.

Although molecular layers obtained by self-assembly produce materials potentially useful for application in electronics and sensors, it is advantageous to lock the assembly by covalent bonding to secure the mechanical and thermal stability of the structure and increase the intermolecular electron transport, obtaining extended $\pi$-conjugated networks, more suitable for technological applications $[8,66-70]$. The $\pi$-conjugation ensures the electron transport along the molecular backbone, as first demonstrated for electrical conductivity in polyacetylene in 1977 [71].

The synthesis of $\pi$-conjugated polymers in solution is well-established and can be applied on industrial scales, yet it typically yields disordered structures [72]. An alternative method to improve their structural order is represented by on-surface synthesis, which uses a substrate to confine the growth onto a 2D plane and, sometimes, to catalyze the reaction. The choice of precursor molecules with different degrees of branching (i.e. on the number and position of the active sites) permits extended layers with the desired 1D or 2D architectures with different electronic properties to be obtained. This has been highlighted by density functional theory (DFT) calculations reporting the band-gap engineering of a polymeric layer by changing its structure and dimensionality [12]. Defects in the structure may limit the electric charge transport, since the $\pi$-conjugated backbone is interrupted. In this respect, while 1D chains lose their electron transport ability in the case of defects, 2D polymers offer more than one path for transferring the electric charge, resulting in an increased efficiency. The order of these nanostructures is an important aspect to increase the charge transport performances, since the path length of the electric charge is increased for disordered structures. The formation of covalent bonds between molecular building blocks on surfaces has recently been reported by several groups, as will be shown in the following, and opens the door to the creation of polymeric architectures which are impossible to access by standard reactions in solution [73-74].

Surface-confined polymerization allows the realization of graphene-like networks, with important advantages. As introduced above, graphene possesses appealing properties, that may be changed by post-modification [75]. As an alternative, the graphene-like moieties created upon surface-confined polymerization can be arbitrarily designed. The geometry and chemical composition of the final structures can be changed upon careful choice of the precursor molecules used for the synthesis, increasing the degree of freedom in engineering the desired nanostructure and allowing the fine 
tuning of its electronic properties. This approach opens the way to $2 \mathrm{D} \pi$-conjugated organic functional devices built up from organic molecules.

Several approaches, exploiting different types of surface-confined reactions, irreversible or reversible, have been reported. These studies have been performed at the solid-vacuum (in UHV), solid-air (in ambient conditions) or solid-liquid interfaces. The polymerization may proceed upon external stimuli, such as thermal treatments, light irradiation, STM tip action, voltage pulses or by a change of the $\mathrm{pH}$ of the solution. In all cases, one or more types of precursor molecule are used and activated to bind each other, forming the polymers [66-67, 76-82]. In the following, the most significant results reported in literature exploiting different types of on-surface chemical reactions will be briefly discussed. An overview of the first results concerning surface-confined covalent coupling will be provided, followed by a section dedicated to the Ullmann coupling, one of the most used reactions in this field, and a brief description of other chemical reactions. Table 1 summarize the most important information for these works, and Scheme 1 reports the corresponding reaction schemes.

\begin{tabular}{|c|c|c|c|c|}
\hline Reaction & Ambient & Dim. & Stimulus & Surface and reference \\
\hline \multirow{4}{*}{ Ullmann coupling } & \multirow{3}{*}{ UHV } & $0 \mathrm{D}$ & Heat & $\mathrm{Cu}(111)[83-84]$ \\
\hline & & $1 \mathrm{D}$ & Heat & $\begin{array}{l}\mathrm{Au}(111)[85-90] \mathrm{Ag}(111)[91] \\
\mathrm{Cu}(111)[92] \mathrm{Cu}(110)[93-98] \\
\mathrm{NaCl} / \mathrm{Au}(111)[87] \mathrm{Au}(100)[89] \\
\mathrm{CaCO}_{3}[99] \mathrm{TiO}_{2}[100-101]\end{array}$ \\
\hline & & $2 \mathrm{D}$ & Heat & $\begin{array}{l}\mathrm{Au}(111)[85,89,102-103] \mathrm{Cu}(111) \\
{[102,104] \mathrm{Ag}(111)[102,105-106]} \\
\mathrm{Au}(100)[89]\end{array}$ \\
\hline & Solution & $1 \mathrm{D}$ & Heat & $\mathrm{Au}(111)$ in nonanoic acid [107] \\
\hline \multirow[t]{2}{*}{$\begin{array}{l}\text { Ullmann coupling } \\
+ \text { Cyclo- } \\
\text { dehydrogenation }\end{array}$} & \multirow[t]{2}{*}{ UHV } & \multirow[t]{2}{*}{$1 \mathrm{D}$} & Heat & $\begin{array}{l}\mathrm{Au}(111)[108-111] \mathrm{Ag}(111)[110, \\
\text { 112] } \mathrm{Cu}(111)[113] \mathrm{Au}(110)[108, \\
114]\end{array}$ \\
\hline & & & STM-tip & $\mathrm{Au}(111)[115]$ \\
\hline $\begin{array}{c}\text { Cyclo- } \\
\text { dehydrogenation }\end{array}$ & UHV & 0D & Heat & $\begin{array}{l}\operatorname{Pt}(111)[116] \mathrm{Cu}(111)[117] \\
\mathrm{Au}(111)[118]\end{array}$ \\
\hline Radical addition & UHV & $1 \mathrm{D}$ & Heat & $\mathrm{Cu}(110)$ [119-120] \\
\hline \multirow{4}{*}{$\begin{array}{l}\text { Boronic acid } \\
\text { condensation } \\
\text { (BAC) }\end{array}$} & \multirow{3}{*}{ UHV } & \multirow{3}{*}{$2 \mathrm{D}$} & Heat & $\operatorname{Ag}(111)[121]$ \\
\hline & & & STM-tip & $\operatorname{Ag}(100)[122]$ \\
\hline & & & $\mathrm{e}^{-}$-beam & $\operatorname{Ag}(100)[122]$ \\
\hline & Ambient & $2 \mathrm{D}$ & Heat & HOPG [123-127] \\
\hline $\begin{array}{l}\text { BAC + Ullmann } \\
\text { coupling }\end{array}$ & UHV & $2 \mathrm{D}$ & Heat & $\mathrm{Au}(111)[128]$ \\
\hline \multirow{2}{*}{$\begin{array}{l}\text { Carbonyl- } \\
\text { analogue addition }\end{array}$} & \multirow[b]{2}{*}{ UHV } & $1 \mathrm{D}$ & Heat & $\mathrm{Au}(111)[129-130]$ \\
\hline & & $2 \mathrm{D}$ & - & $\begin{array}{l}\mathrm{Au}(111)[131] \mathrm{Ag}(111)[131] \\
\mathrm{NaCl} / \mathrm{Ag}(100)[131]\end{array}$ \\
\hline \multirow[b]{2}{*}{$\begin{array}{l}\text { Schiff-base } \\
\text { coupling }\end{array}$} & UHV & 0D & Heat & $\mathrm{Au}(111)[132-133]$ \\
\hline & Solution & 0D & - & $\begin{array}{l}\text { Silicon in toluene [134] } \\
\text { HOPG in 1-phenyloctane [135] }\end{array}$ \\
\hline
\end{tabular}




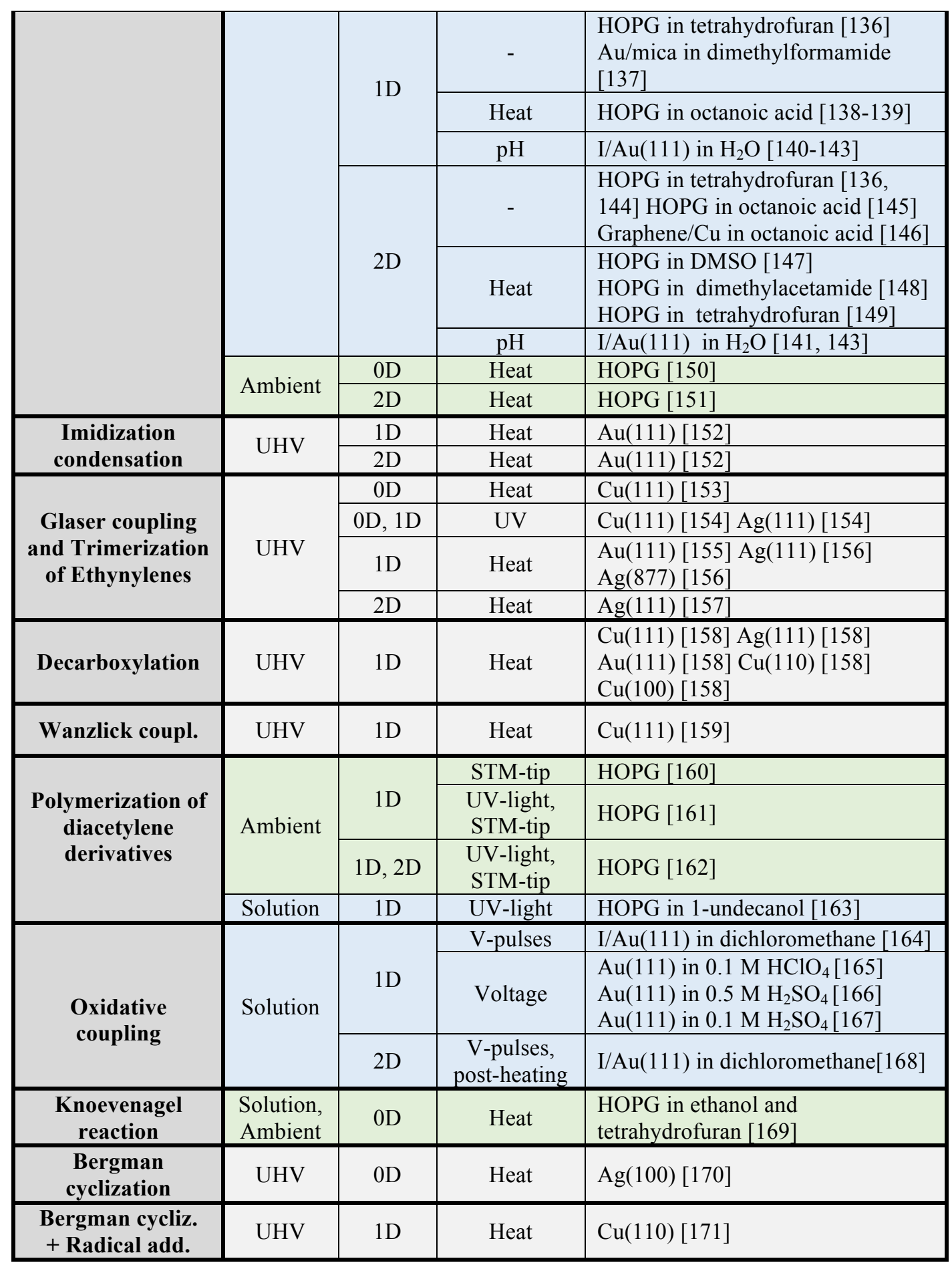

Table 1. The most significant results concerning surface-confined coupling and polymerization reported in literature, classified as a function of the reaction type, ambient at the interface, dimensionality of the obtained nanostructures, stimuli (if present), surface and solution used (for solid-liquid interface). Metal-catalyzed dehalogenative reactions are grouped together in the Ullmann coupling section, even if substrates other than copper are used. The corresponding reaction schemes are reported in Scheme 1. 


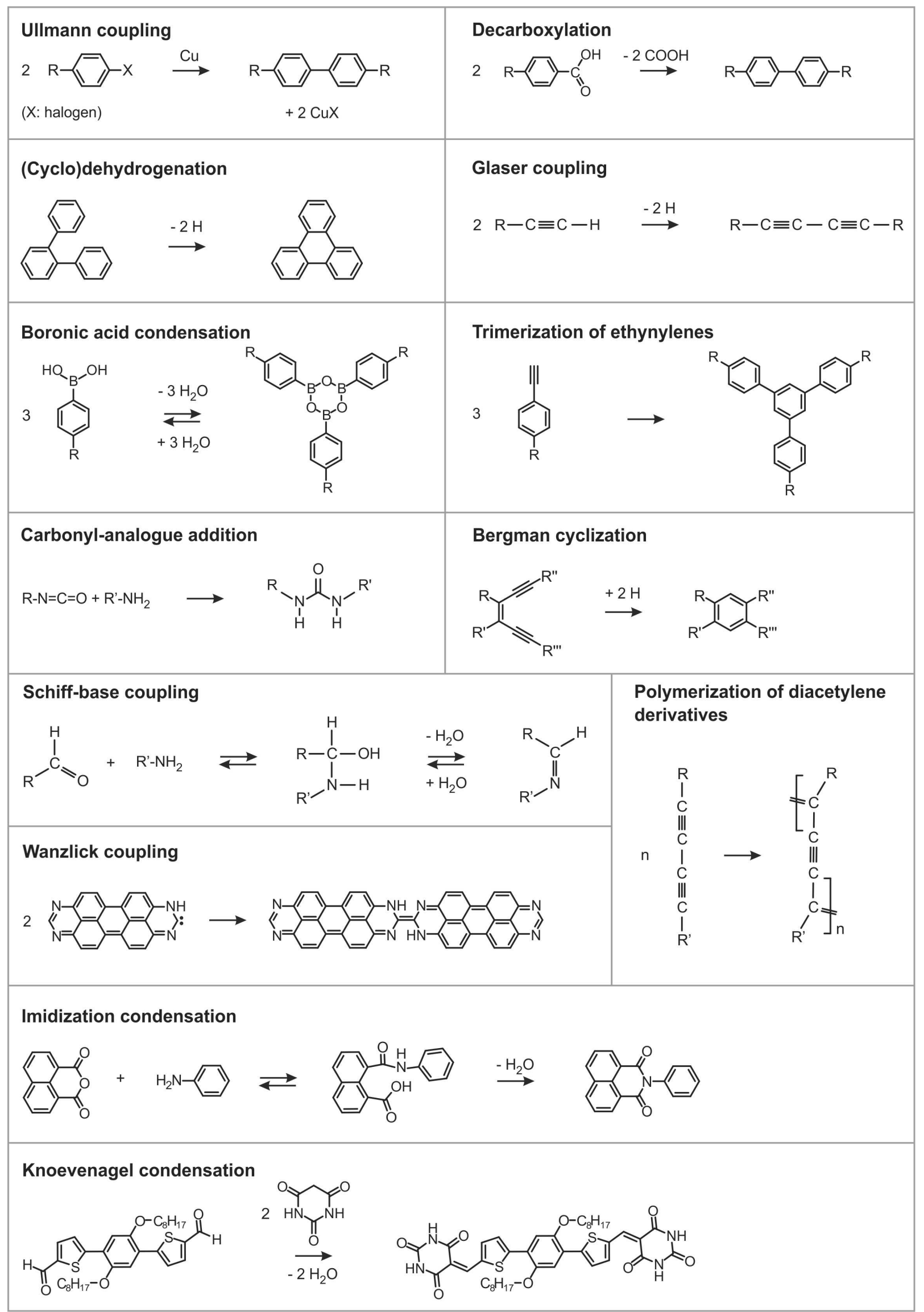

Scheme 1. Examples of reaction schemes of the processes reported in Table 1. 


\subsection{Covalent coupling on surfaces}

The road to the understanding of the processes leading to the formation of extended $\pi$-conjugated polymers on surfaces originates from the study of the coupling reactions between organic molecules, producing final covalently-linked structures that in some cases are constituted of few molecular units (oligomers). Some of the first examples of molecular coupling on surfaces appeared in 1992, reporting the Ullman reaction (Scheme 1) studied by temperature-programmed desorption (TPD) spectroscopy [172-174]. The imaging of a coupling product appeared a few years later, when the chemical steps of biphenyl formation from iodobenzene precursors on $\mathrm{Cu}(111)$ upon Ullmann coupling have been induced and imaged by the tip of an STM [175]. Recently, details on the selectivity involving Ullmann coupling have been reported for the cross-coupling reaction between bromobenzene and 4-ethylbromobenzene [84]. Another case of covalent coupling producing 0D structures on surfaces is represented by the formation of $\mathrm{C}_{60}$ and $\mathrm{C}_{57} \mathrm{~N}_{3}$ (triazafullerene) upon catalytic cyclodehydrogenation from different aromatic precursors deposited on $\operatorname{Pt}(111)$ in UHV, and annealing the surface to $750 \mathrm{~K}$. This approach may allow the production of a range of other fullerenes and heterofullerenes and, if the process is carried out in an atmosphere containing guest species, it might even allow the encapsulation of atoms or small molecules into the fullerene core [116].

One of the first reactions used to synthesize longer chains (polymers) on surfaces involves diacetylene derivatives, a class of molecules that have been extensively studied in ambient conditions and at the solid-liquid interface without any thermal treatment. An isophthalic acid derivative has been observed to self-assemble on HOPG after drop casting in 1-undecanol, forming an alternate lamellar structure interspersed with the solvent molecules. After UV irradiation for 30 minutes, the formation of polydiacetylene moieties induces changes in the morphology [163]. The same 1D structures are observed by applying a voltage pulse $(4 \mathrm{~V}, 10 \mu \mathrm{s})$ to the STM-tip. The polymerization starts in the point where the pulse is applied and propagates in the ordered domain only due to thermal energy and terminates when it encounters the domain boundary or a defect intentionally created, demonstrating the possibility of controlling the formation and termination of the polymeric chains with nanometer precision (Figure 2a) [160-161]. These approaches have been extensively exploited to form polymeric structures on HOPG, carefully describing the geometry of the reaction products and their modification observed using different precursors. After random 1D polymerization induced by UV-light, a single-pulse from the STM-tip produced additional 
polymeric chains which coupled with the former creating small 2D covalently-linked structures (Figure 2b) [162].

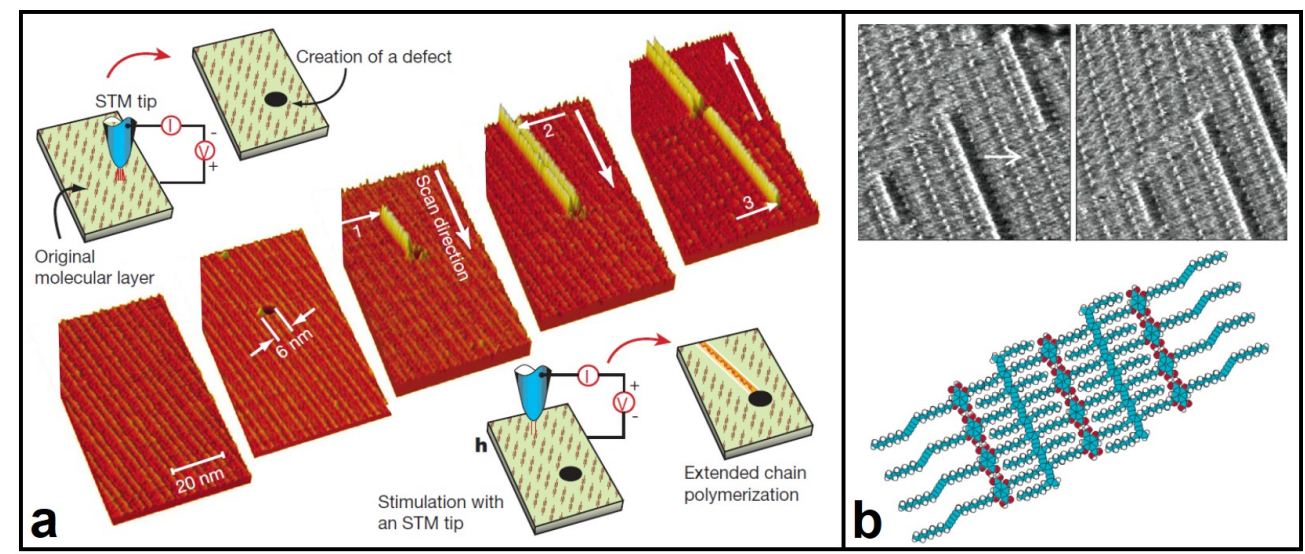

Figure 2. a: STM images and sketches showing the possibility of controlling the initiation and termination of linear chain polymerization with an STM tip [160]. Adapted with permission from Nature Publishing Group, copyright 2001. b: STM image of self-assembled molecules after $30 \mathrm{~min}$ of UV light irradiation. A voltage pulse was applied using the STM tip at the position indicated with a white arrow. The resulting surface is shown in the right panel, where a polydiacetylene backbone appears after the pulse (corresponding to the model in the bottom panel) [162]. Adapted with permission from American Chemical Society, copyright 2003.

\subsection{Ullmann coupling}

Concerning the production of extended polymeric networks at surfaces one of the most used methods exploits Ullmann coupling, a copper-catalyzed two-step reaction involving aryl halides as precursor molecules (Scheme 1). In some cases, a metal other than copper is used, but similar dehalogenative aryl-aryl coupling is observed: we will indicate these as Ullman-like processes. This reaction has proven to be a promising fabrication method for extended $\pi$-conjugated polymers with desired architectures (dimers, 1D and 2D polymers). The number and position of the active sites in the precursor molecules affects the geometry of the final polymers, as demonstrated by L. Grill et $a l$. by using three different porphyrin-based precursor molecules with one $\left(\mathrm{C}_{1}\right.$ symmetry), two (in para position, $\mathrm{C}_{2}$ symmetry) or four ( $\mathrm{C}_{4}$ symmetry) Br substituents on $\mathrm{Au}(111)$ (Figure 3a) [85].

Dimensional control is further demonstrated in the case of bifunctional haryl halides: 1,3- and 1,4diiodobenzene on $\mathrm{Cu}(110)$ form zig-zag and linear 1D polymers, respectively. The intermediate (organometallic) states and the final polymers display significant morphological differences and the substrate is found to act as a template, ordering the polymers along its principal crystalline direction (Figure 3b) [94]. This thermally activated polymerization pathway has been observed by STM also 
for poly(3,4-ethylenedioxythiophene) on $\mathrm{Cu}(110)$ showing the formation of a reactive intermediate (copper-bound thiophene biradical) followed by the production of dimers, trimers, tetramers, and longer oligomers [95].

With the aim of obtaining porous graphene starting from organic molecules, trifunctional precursors with $\mathrm{C}_{3}$ symmetry have been studied. As an example, 1,3,5-tris-(4-bromophenyl)benzene molecules have been found to self-assemble through halogen-hydrogen interactions when deposited on graphite(001), while dehalogenation is observed on $\mathrm{Cu}(111)$ at room temperature (RT). Annealing of the $\mathrm{Cu}(111)$ to $570 \mathrm{~K}$ produces the formation of 2D covalent-organic frameworks (COFs), while thermal treatment of graphite(001) leads to the desorption of molecules before the polymerization. These observations demonstrate the importance of the substrate in driving the first and second steps of the reaction (formation of the organometallic phase and covalent coupling) [104]. The same precursor on $\mathrm{Au}(111)$ produces self-assembled dimers and 2D polymeric structures upon annealing the surface at $110{ }^{\circ} \mathrm{C}$ and $180{ }^{\circ} \mathrm{C}$, respectively (Figure $3 \mathrm{c}$ ). The obtained open pore network have been used to host $\mathrm{C}_{60}$ molecules: as a function on the pore dimension, one or more fullerenes can be hosted in each pore [103]. In these works, the pores of the graphene-like molecular networks present different geometries (pentagons, hexagons, heptagons and other polygons) with a wide size distribution. Narrower distribution of the pore size has been obtained using larger halogenated molecules, such as hexaiodo-substituted macrocycle cyclohexa-m-phenylene (CHP), on $\operatorname{Ag}(111)$ [105].

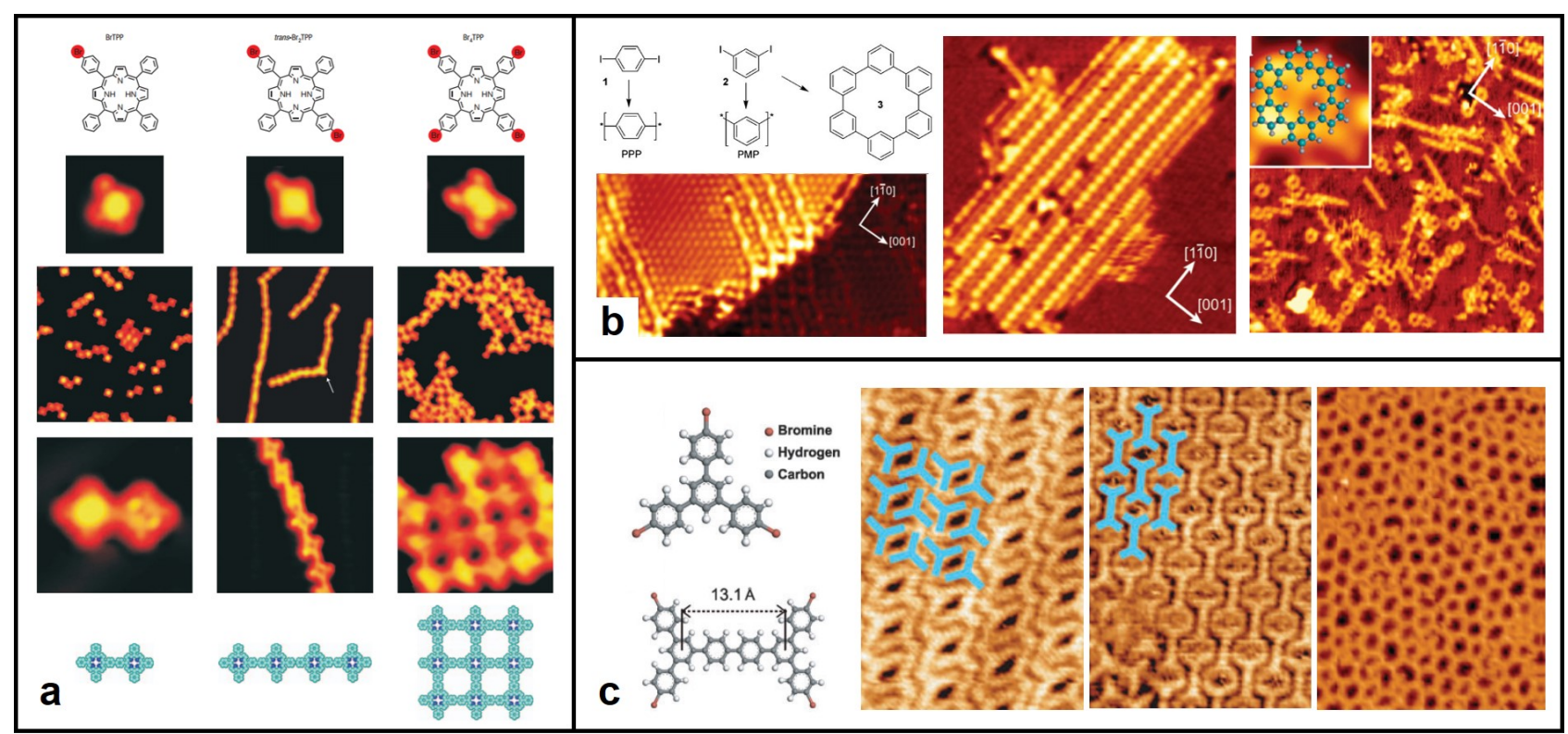

Figure 3. a: On-surface synthesis of dimers, 1D polymers and 2D networks exploiting Ullmann-like coupling from a porphyrin-based precursor with different number of bromine substituents [85]. Adapted with permission from Nature Publishing Group, copyright 2007. b: Formation of poly(para-phenylene) chains from an aromatic precursor containing 
iodine atoms. Depending on the position of the halogens, straight polymers, zigzag chains or macrocycles can be obtained [94]. Adapted with permission from John Wiley and Sons, copyright 2009. c: Self-assembly and coupling of a trifunctional precursor, forming dimers at $383 \mathrm{~K}$ or creating a 2D covalent network when deposited on $\mathrm{Au}(111)$ held at 413 K [103]. Adapted with permission from the Royal Society of Chemistry, copyright 2010.

Ullmann-like coupling has been investigated in detail in order to provide insights into the mechanism leading to the formation of the polymers. On $\mathrm{Au}(111)$ different metal adatoms (Pd and $\mathrm{Cu}$ ) were added on the substrate to study their effect on the polymerization mechanism of 5,15-bis(4-bromo-phenyl)-10,20-diphenyl porphyrin precursors. The Pd-catalyzed reaction produces shorter chains, with lower yield of polymer formation compared to the Cu-catalyzed one. Moreover, the yield of the $\mathrm{Cu}$-catalyzed reaction significantly increases at high temperatures (around $400 \mathrm{~K}$ ). Kinetic Monte Carlo (KMC) simulations indicate that the polymerization can be modeled as a twostep process: activation of the $\mathrm{C}-\mathrm{Br}$ bond and subsequent formation of the $\mathrm{C}-\mathrm{C}$ linkage. The ratelimiting step is found to be the former or the latter if using $\mathrm{Cu}$ or Pd adatoms, respectively [86].

Great attention has been devoted to the study of the organometallic intermediate of the surfaceconfined Ullmann coupling and of the complex structures created with the metal atoms of the substrate, using bromobenzene [176] (Figure 4a) or 4,4"-dibromo-p-terphenyl [92] (Figure 4b) as precursor molecules on $\mathrm{Cu}(111)$. In these works, STM investigation unveils the formation of an organometallic bonding between the molecular units and the substrate. In the case of bromobenzene, the observations suggest that the copper atoms bridging two molecules belong to the first atomic plane, rather than being adatoms [176]. However, recent results on the coupling of bromotriphenylene on $\mathrm{Cu}(111)$ suggest that the intermediate step of the Ullmann coupling is coordinated by a $\mathrm{Cu}$ adatom [83]. A clear spectroscopic fingerprint of the different chemical states of the molecules undergoing Ullmann coupling on $\mathrm{Cu}(110)$ has been provided using 1,4dibromobenzene as a molecular precursor [93, 177]. X-ray photoelectron spectroscopy (XPS) and near-edge X-ray absorption fine structure (NEXAFS) spectroscopy identify the organometallic bonding as an intermediate step of the coupling towards $\pi$-conjugated polymers (Figure $4 \mathrm{c}$ ). In the same work, the active role of the halogen in driving the polymerization is also reported as a new insight into the process. This aspect has been further analyzed for a series of dihalobenzenes, showing that not only the precursor geometry, but also the halogen type affects the morphology of the polymeric structures [178]. A full description of the electronic band structure of $\operatorname{poly}(p$ phenylene) (PPP) polymers has also been reported. A combination of STS and ARPES measurements show a band gap of $1.15 \mathrm{eV}$ and a metallic behavior of organic nanowires (Figure 4d) [96]. 
The conductance of a single polymeric chain has been measured between an $\mathrm{Au}(111)$ surface and the STM-tip. Dibromoterfluorene precursors form 1D polyfluorenes upon Ullmann-like coupling, arranged on the surface along the grooves of the gold herringbone reconstruction. By pulling one of these chains with the STM-tip, its conductance has been measured as a function of the molecular length [88].

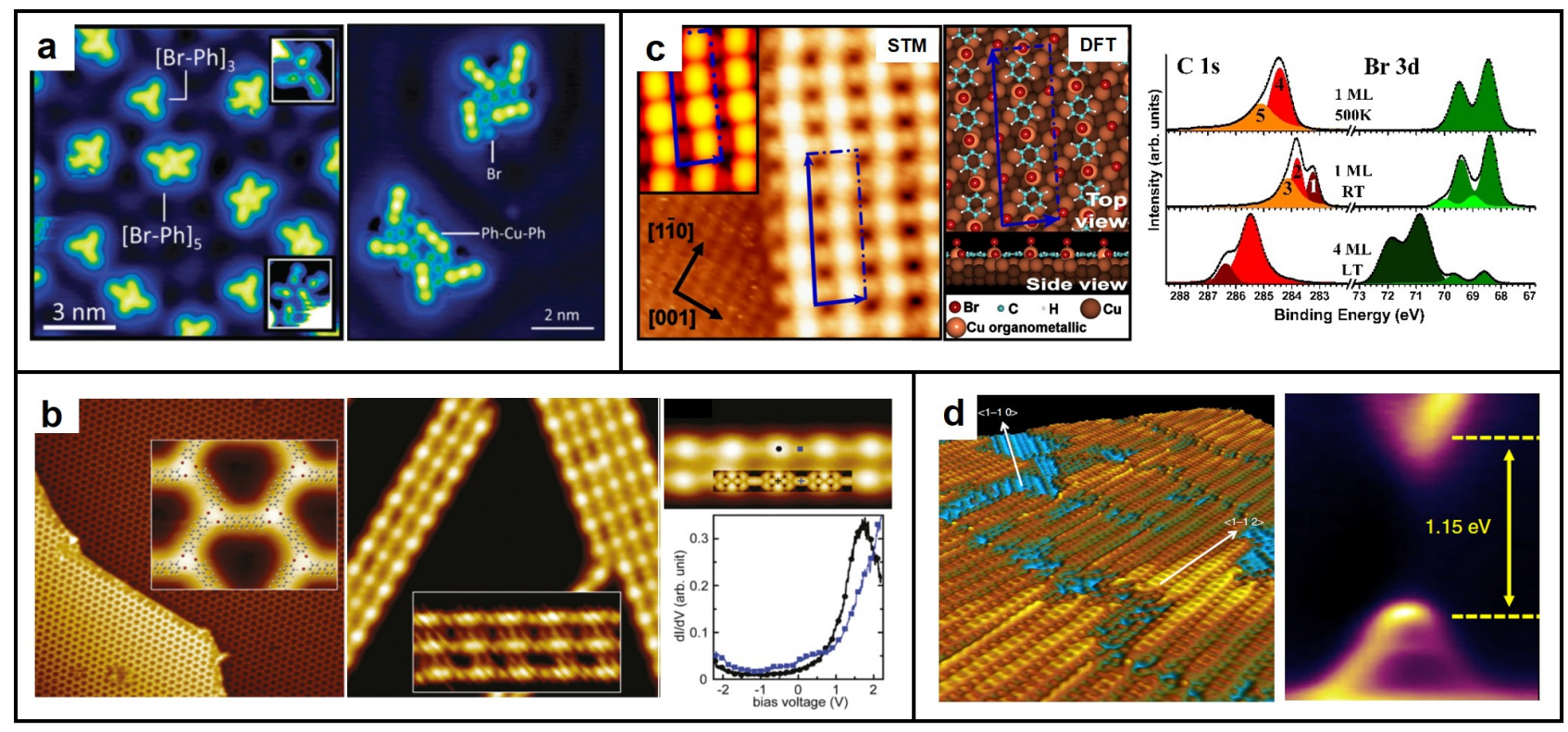

Figure 4. a: STM investigation of the intermediate organometallic phase in Ullmann coupling of bromobenzene, showing the $\mathrm{Ph}-\mathrm{Cu}-\mathrm{Ph}$ bridge after annealing at $180 \mathrm{~K}$ on $\mathrm{Cu}(111)$ [176]. Adapted with permission from the Royal Society of Chemistry, copyright 2013. b: Formation of poly(para-phenylene) showing the intermediate organometallic bonding between dibromoterphenyl precursor mediated by $\mathrm{Cu}(111)$. $\mathrm{d} / \mathrm{dV}$ spectra reveal the spectroscopic difference between the terphenyl units and the $\mathrm{Cu}$ atom bridging the monomers [92]. Adapted with permission from the American Chemical Society, copyright 2011. c: Organometallic chains formed as intermediate step of Ullmann coupling from 1,4dibromobenzene on $\mathrm{Cu}(110)$ at RT. XPS and NEXAFS spectroscopies reveal further details of the coupling process [93]. Adapted with permission from the American Chemical Society, copyright 2013. d: The electronic properties of poly(para-phenylene) chains on $\mathrm{Cu}(110)$ have been investigated, showing an electronic band gap of $1.15 \mathrm{eV}$. Adapted with permission from Nature Publishing Group, copyright 2016 [96].

\subsection{Other chemical reactions}

Dehalogenative aryl-aryl coupling has also been used in the framework of mixed strategies, together with dehydrogenation reactions (Scheme 1), to obtain graphene nanoribbons (GNRs). 10,10'dibromo-9,9'-bianthryl precursor monomers have been studied on Au(111) in UHV by STM. In the first step, dehalogenation takes place forming polyantrylene linear chains by aryl-aryl coupling upon thermal activation at about $500 \mathrm{~K}$. In the second step, at about $670 \mathrm{~K}$, cyclodehydrogenation 
and consequent coupling into linear armchair GNRs (AGNRs) have been obtained (Figure 5a) [110]. The coupling of such precursors has been spectroscopically investigated both on $\mathrm{Au}(111)$ and $\mathrm{Au}(110)$ [108]. By using 6,11-dibromo-1,2,3,4-tetraphenyltriphenylene as a precursor monomer, zig-zag GNRs (ZGNRs) can be grown with the same procedure on $\operatorname{Au}(111)$ and $\operatorname{Ag}(111)$. Combining two different precursor monomers makes it possible to obtain GNR heterojunctions, as demonstrated with 1,3,5-tris(4"-iodo-2'-biphenyl)benzene $\left(\mathrm{C}_{3}\right.$ symmetry) leading to the formation of a threefold GNR junction [110]. Intraribbon heterojunctions have been realized via temperatureinduced partial cyclodehydrogenation of a surface-anchored polyanthrylene chain. Ullmann-like coupling has been used as first reaction step; annealing at about $600 \mathrm{~K}$ leads to cyclodehydrogenation of one side of the ribbon, while annealing at $670 \mathrm{~K}$ fully dehydrogenates the ribbon, achieving a completely flat geometry. The boundary between these two structures produces GNR heterojunctions (Figure 5b). Cyclodehydrogenation has also been locally activated in selected units of the ribbons by electron injection from the STM-tip [115]. Investigation on the same precursor molecules on $\mathrm{Cu}(111)$ reveals the possibility of growing zig-zag chiral-edges GNRs with the edges aligned to the crystalline directions of the substrate, altering previously studied reaction pathways by specific properties of the substrate. This method opens possibilities for enantioselective heterogeneous catalysis [113].

GNRs obtained by sequential Ullmann-like coupling and dehydrogenation processes have also been obtained using 4,4"-dibromo-p-terphenyl on Au(111). First, 1D poly(para-phenylene) polymers are obtained by annealing at about $400 \mathrm{~K}$, then these chains are laterally fused by dehydrogenation at about $650 \mathrm{~K}$ (Figure 5c). A fine balance involving gold catalytic activity in the first coupling step, molecular mobility, and favorable topochemical conditions (provided by the used precursor) leads to a high degree of long-range order that characterizes each step of the synthesis [111]. The interplay among the different factors driving the formation of these structures has been investigated by growing GNRs on both $\mathrm{Au}(110)$ and $\mathrm{Au}(111)$ also by means of spectroscopic investigation, revealing that the low molecular mobility due to the $\mathrm{Au}(110)$ corrugation is the main factor limiting GNR length and density, compared to other surfaces, even a highly interacting surface such as $\mathrm{Cu}(111)$ [114]. The possibility of engineering the final shape of GNR has been demonstrated by the numerous studies reported in the literature [179], together with the deep investigation of their electronic properties and conformational features (as the edge connectivity, illustrated in Figure 5d) [109, 180-184]. 


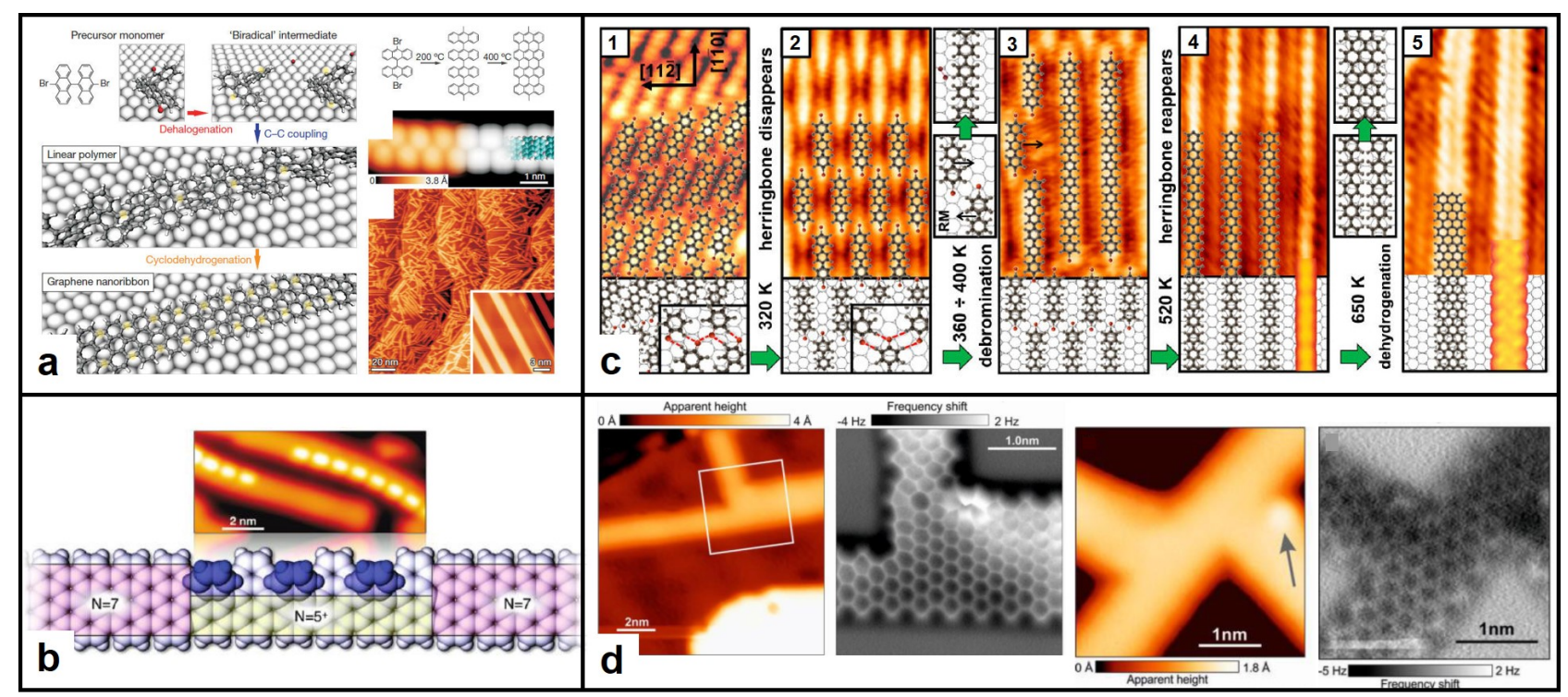

Figure 5. a: Synthesis of atomically precise 7-AGNRs via Ullmann-like coupling and subsequent cyclodehydrogenation occurring at $473 \mathrm{~K}$ and $673 \mathrm{~K}$, respectively [110]. Adapted with permission from Nature Publishing Group, copyright 2010. b: GNRs can be used to realize intraribbon heterojunctions by partial cyclodehydrogenation of polyanthrylene oligomers [115]. Adapted with permission from the American Chemical Society, copyright 2012. c: GNRs can be synthesized by laterally fusing together 1D polymers, as shown by the STM images revealing different structures obtained as a function of the increasing temperature [111]. Adapted with permission from the American Chemical Society, copyright 2015. d: The connectivity between GNRs can be investigated to gain information of different junction moieties [183]. Adapted with permission from the American Chemical Society, copyright 2015.

Ullmann-like coupling has also been performed at the solid-liquid interface on $\mathrm{Au}(111)$. Dimer formation from 1,3,5-tri(4-bromo-phenyl)benzene precursors has been observed but the growth of extended 2D polymers is prevented due to the low mobility of the dimers [185]. A precursor with same architecture including iodine instead of bromine at the active sites (1,3,5-tri(4-iodophenyl)benzene) was found to form 2D polymeric networks: this has been possible thanks to the formation of iodine domains that act as deactivators of the catalytic surface, increasing the mobility of the precursor molecules. However, the polymers are not long-range extended because the iodine adlayer poisons the $\mathrm{Au}(111)$ surface inhibiting any further catalytically supported iodine homolysis and preventing a complete dehalogenation of the precursor molecules [107].

Besides Ullmann-like coupling, various types of reactions have been exploited in UHV to obtain extended surface-confined polymers. Imidization condensation (Scheme 1) has been used to form polymers on $\mathrm{Au}(111)$ in UHV upon annealing of the surface: 1D or 2D polyimides can be obtained by changing the geometry of the precursor molecules (dianhyidrides coupled with di- or triamines, respectively) [152].

Dehydrogenation reactions have been used to modify intramolecular structure (forming new covalent bonds) or to produce extended $\pi$-conjugated COFs on surfaces, as introduced above for the 
formation of GNR. The use of C-H bonds, present in all organic molecules, activated by metal surfaces to produce $\mathrm{C}-\mathrm{C}$ bonds with no byproduct on the surface, elects this to a general approach for on-surface nanofabrication. The cyclodehydrogenation of a prototypical polyphenylene (cyclohexa-o-p-o-p-o-p-phenylene) on $\mathrm{Cu}(111)$ in UHV has been reported showing that thermally activated dehydrogenation leads to the formation of intramolecular covalent bonds, producing tribenzocoronenes. The catalytic role of the substrate has been studied and the reaction pathway has been identified, based on ab initio simulations: six steps, through five reaction intermediates, lead to a completely planar final geometry [117]. Dehydrogenation plays a key role in the design for bottom up construction of complex macromolecules, as shown for the formation of fullerenes [116]. This is a promising route to obtain nanostructures with the desired geometry and functionality, exploiting the central challenge to discover universal connection strategies that are applicable to a wide range of molecules: "pick-mix-and-link" strategies have been shown to generate libraries of multivariate macromolecules on $\mathrm{Cu}(110)$, mainly based on porphyrins and arenes as precursors. Unfortunately, in this case a selective control of the coupling process is still lacking [119-120].

Decarboxylation (Scheme 1) has also been demonstrated to be an effective method to obtain 1D polymers on metal surfaces in UHV: poly-2,6-naphthalenes has been formed using prochiral 2,6naphthalene dicarboxylic acid as a precursor on several metal surfaces. Different reactivities of the substrates, decreasing in the order $\mathrm{Cu}(111)>\mathrm{Cu}(100)>\mathrm{Ag}(111)>\mathrm{Cu}(110)>\mathrm{Au}(111)$, is likely to be related to the ability of metal atoms to be pulled out of the surface to catalyze the reaction [158]. Carbonyl-analogue addition (Scheme 1) is a byproduct-free reaction that drives the coupling of 1,4diaminobutane with 1,3- and 1,4-phenylene diisocyanate on $\mathrm{Au}(111)$ in UHV, producing polyurea oligomers as a function of the substrate temperature [129]. This method has been exploited with different precursors, namely 1,4-phenylene diisocyanate and melamine, but in this case polyurea oligomers were never longer than eight units, therefore limiting possible application for real-life devices [130]. Carbonyl-analogue addition is also the mechanism responsible of the formation of long-range ordered 2D iron phthalocyanine polymers on $\mathrm{Au}(111)$ and $\mathrm{Ag}(111)$ using 1,2,4,5tetracyanobenzene and Fe atoms in 2:1 stoichiometry. On the other hand, a 4:1 ratio only leads to individual phthalocyanine molecules self-assembling on the surface. A noticeable step ahead has been made by growing such a poly-phthalocyanine network on $\mathrm{NaCl}$ islands formed on $\mathrm{Ag}(100)$ : the quality and extension of the $2 \mathrm{D}$ polymeric network promote this as a promising method to grow conducting nanostructures on insulators [131].

Different types of coupling have been shown to occur for the thermally activated reaction of 1,4diethynylbenzene on $\mathrm{Cu}(111)$ in UHV. While a H-bond stabilized self-assembled structure is observed after RT deposition of the precursor molecules, following annealing to $573 \mathrm{~K}$, new 
features appear on the surface, and are ascribed to connected molecules following Glaser-type coupling and trimerization pathways (Scheme 1) and a combination of the two [153].

Another interesting example of surface-confined polymerization is reported for $1,3,8,10$ tetraazaperopyrene on $\mathrm{Cu}(111)$ in UHV. Here, the precursor molecules form a so called coordination polymer at about $423 \mathrm{~K}$, coordinating to $\mathrm{Cu}$ atoms through the nitrogen lone pairs. Annealing this structure to $523 \mathrm{~K}$ produces the formation of polymers: the reaction is thought to occur through the tautomerization of the N-heterocyclic end units, which couple according to a Wanzlick-type mechanism (Scheme 1) [159].

The use of an electric potential allows polymers to be created at the solid-liquid interface, by exploiting the oxidative coupling. Electropolymerization has been investigated on an iodinecovered $\mathrm{Au}(111)$ surface immersed in solution with a three-electrode arrangement: 3-octyloxy-4methylthiophene and 3-octyl-4-methylthiophene are used as precursor molecules to form copolymers. Voltage pulses ( 35 pulses of $1.2 \mathrm{~V}, 150 \mathrm{~ms}$ long) are applied to the sample and oxidize the monomers, leading to the formation of $1 \mathrm{D}$ polymers. Repeating this procedure in solutions containing different monomers allows heteropolymers to be synthesized on the surface, obtaining heterojunctions at the connection point between two different strands [164]. A similar method, combined with thermal activation, has been used to increase the length of the polymers [168]. The electrochemical oxidative polymerization of aniline represents another type of approach performed in a three-electrode cell: at a suitable working electrode potential, the oxidation of anilines to cation radicals and the intermolecular coupling between aniline molecules to form polyaniline were observed. Linear polyaniline chains grow in epitaxial fashion up to four molecular layers on $\mathrm{Au}(111)$ [166-167]. In some cases, this type of process has been found to occur via polymerization in the solution and subsequent adsorption of the polymeric chains on the surface [165].

Recently, other reactions usually adopted in solution chemistry have been applied to the surfaceconfined synthesis, such as the Knoevenagel reaction (Scheme 1), successfully performed at the liquid-solid and vapor-solid interfaces for the condensation of 2,5-di(5-aldehyde-2-thienyl)-1,4dioctyloxybenzene and barbituric acid precursors on HOPG [169]. Bergman cyclization (Scheme 1) has also received great attention: it has been investigated by monitoring the chemical reaction of 1,2-bis((2-ethynylphenyl)ethynyl) upon annealing in UHV on $\operatorname{Ag}(100)$ by non-contact atomic force microscopy (nc-AFM). The formation of each new bond during the cyclization process has been monitored, paving the way for the rational synthesis of complex functional molecular architectures [170]. 1D polymers have also been obtained using the Bergman cyclization followed by radical polymerization: 1,6-di-2-naphthylhex-3-ene-1,5-diyne precursor molecules undergo cyclization 
upon annealing on $\mathrm{Cu}(110)$ in $\mathrm{UHV}$, forming an aromatic ring bearing two radical sites which bind each other forming polyphenylene chains [171].

Successful results have also been obtained using Schiff-base coupling and the condensation of boronic acid derivatives. These approaches will be discussed in the following, as their reversibility represents a crucial aspect to increase the size of ordered domains on the surface.

\section{Challenges of surface-confined polymerization}

All the works reported above are important examples of surface-confined synthesis of organic nanostructures. As a result, the understanding of the mechanisms driving the polymerization processes has enormously advanced. However, one of the main goals of the research on such lowdimensional conducting polymers is their inclusion in devices relevant for real-life applications. This is challenging due to two main bottlenecks: (i) the growth on metal substrates, that inhibits the use of the organic networks as active media in electronic and optoelectronic devices, and (ii) the often poor long-range order, especially of two-dimensional (2D) networks, needed to increase the efficiency in the electric charge transport.

Concerning the first challenge, the transfer of the organic layer to different substrates is possible, e.g. by mechanical peeling [186] or electrochemical exfoliation followed by the chemical etching of the metal underneath [187-188]. However, there is also an interest in performing the synthesis directly on non-metallic surfaces, to avoid any transfer step that might damage the polymeric layer. One possibility is represented by insulating thin films pre-deposited on metal surfaces. $\mathrm{NaCl}$ has been grown on $\mathrm{Au}(111)$ where 1D poly(9,9-dimethylfluorene) was previously synthesized by Ullmann-like coupling from dibromoterfluorene. The polymers are preferentially adsorbed on the metal surface, but increasing the size of $\mathrm{NaCl}$ islands (at higher exposure) some chains rise on top of these islands thanks to their surface mobility and are lifted from the $\mathrm{Au}(111)$ surface allowing the study of their electronic properties when decoupled from the metal substrate (Figure 6a) [87]. Ordered 2D polymeric phthalocyanine have been obtained by carbonyl-analogue addition on $\mathrm{NaCl}$ islands grown on $\operatorname{Ag}(100)$ upon co-evaporation of $\mathrm{Fe}$ and 1,2,4,5-tetracyanobenzene, providing a breakthrough in obtaining extended $\pi$-conjugated polymers on insulating substrate (Figure $6 \mathrm{~b}$ ) [131]. Another possibility is the direct synthesis on bulk insulators: this has been investigated on $\mathrm{TiO}_{2}$ and $\mathrm{CaCO}_{3}$ in UHV conditions. In the first case, Ullmann-like coupling of 10,10'-dibromo9,9'-bianthryl precursors occurs on $\mathrm{TiO}_{2}(011)$ (Figure 6c), while the subsequent cyclodehydrogenation expected to form GNRs has not been achieved despite the annealing up to 
$723 \mathrm{~K}$ [100]. The presence of hydroxyl groups on the $\mathrm{TiO}_{2}(011)$ surface has been investigated and correlated to the production of 1D polymers from diiodoterfluorene precursors. Longer polymers are obtained when the surface is covered with a moderate density of hydroxyl groups. On increasing the density of the surface hydroxyls, shorter oligomers are formed, whereas the polymerization reaction is suppressed on a hydroxyl-free surface [101]. Similarly, poly(para-phenylene) chains have been obtained on $\mathrm{TiO}_{2}(110)$ from 4,4''-dibromoterphenyl precursors, and their electronic properties have been investigated in detail [189]. In the second case, freshly cleaved $\mathrm{CaCO}_{3}$ has been used as substrate to deposit 2-(4-bromophenyl)-6-(4-chlorophenyl)pyridine-4-carboxylic acid precursors. Different moieties are observed on the surface, ascribed to dimers, couples of dimers (forming squared structures) and oligomers (forming zigzag chains), exploiting an Ullmann-like coupling after the dissociation of the halogen atoms (Figure 6d) [99].

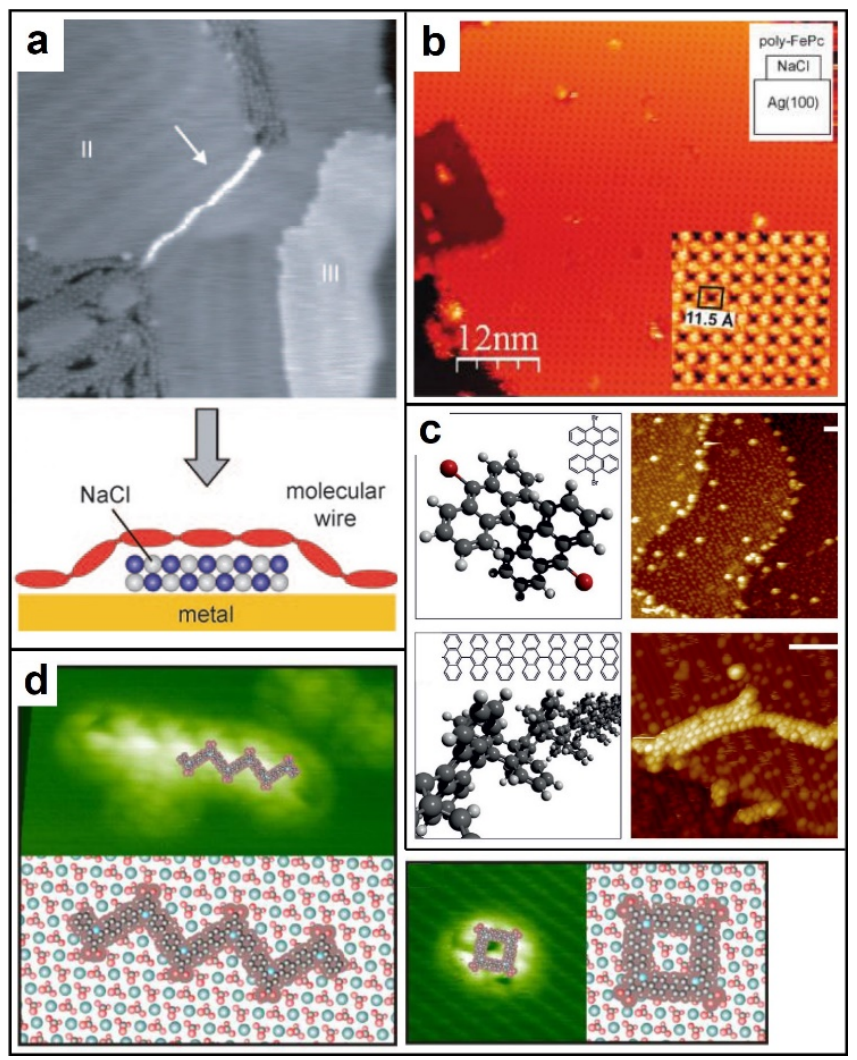

Figure 6. a: Intercalation of $\mathrm{NaCl}$ between polymers and the metal surface represents a possible decoupling method to investigate their electronic properties [87]. Adapted with permission from John Wiley and Sons, copyright 2009. b: Beyond the post-intercalation, it is also possible to directly grow polymers on a $\mathrm{NaCl}$ island, as in the case of FePhtalocyanine networks [131]. Adapted with permission from the American Chemical Society, copyright 2011. Ullmann-like coupling has been triggered under specific condition on insulators, like $\mathrm{TiO}_{2}(011)-(2 \times 1)[100] \mathrm{or} \mathrm{CaCO}_{3}$ [99], reported in panels (c) and (d), respectively. Adapted with permission from John Wiley and Sons, copyright 2013, and from the American Chemical Society, copyright 2013, respectively. 
The second challenge is to achieve long-range ordering of polymeric domains, strictly related on the intermolecular and molecule-substrate interactions. Once organic precursors are deposited on a surface they may diffuse over the substrate and eventually covalently link each other. This behavior resembles the formation of SAMs, where the molecules relate to each other by weak interactions (e.g. van der Waals) in a reversible fashion, enabling the creation of the most energetically stable configuration and producing the growth of 2D islands where the order is extended over the whole domain. The covalent coupling between the building blocks represents an additional step compared to the formation of SAMs. If this coupling step is reversible, there would be a high probability of growing extended polymeric domains, whereas if it is irreversible it would produce less extended domains. However, certain irreversible reactions possess reversible intermediate steps before polymerization that can be exploited to improve the extension of the ordered polymeric nanostructure. The use of entirely reversible reactions or reactions involving reversible steps will be the focus of the following sections.

\section{Reversibility and intermediate steps as key concepts}

The concept of reversibility is at the basis of supramolecular chemistry, which is intrinsically a dynamic chemistry. Materials which are reversible, constitutionally dynamic and capable of modifying their constitution by exchanging, recombining or incorporating components are called dynamers and may behave as adaptive materials [190-191]. Supramolecular and molecular dynamers are characterized by non-covalent and covalent interactions, respectively [192]. This type of materials is of broad interest and has been extensively studied in literature. As an example, exchange between the molecular units of these structures has been observed under acid conditions [193]. The color and fluorescence spectrum of polyhydrazone dynamers can be modified by hydrazone bond exchange and component recombination: this process can occur even at the interface of two different polymer films [194]. Similar approaches enable the development of dynamic mixtures for the controlled release of highly volatile organic molecules [195]. Various $\mathrm{H}-$ bond stabilized supramolecular motifs can be obtained at the solid-liquid interface using different precursor molecules; the switching between them can be controlled by adding suitable extra components (i.e. additional molecules that can be exchanged with part of the existing network), demonstrating high control over the organized organic structure [196-197]. The importance of external stimuli, such as the $\mathrm{pH}$, has been studied and found to affect the 2,6-bis(1-aryl-1,2,3triazol-4-yl)pyridine core from kinked to extended configurations, leading to different self- 
assembled structures. This change of configuration occurs upon addition of trifluoroacetic acid in 1phenyloctane solution and is slower in the case of longer molecular side-chains so that, in some cases, it is possible to observe the coexistence of the two structures [198].

Despite the wide variety of dynamers, their possible configurations and adaptive behavior, the concept of reversibility is less straightforward when dealing with the formation of covalent bonds between molecular building blocks. However, in some particular reactions covalent bonds formed between the organic building blocks may be reverted and isolated molecules can be obtained again. This has been demonstrated on surfaces for two condensation reactions based on a dehydration mechanism, namely the condensation of boronic acid derivatives (Section 4.1) and the Schiff-base coupling (Section 4.2). These processes are based on dehydration reactions: a water byproduct can hydrolyze the covalent bond, proceeding in a dynamic equilibrium. However, when using these methods in UHV conditions, water easily desorbs from the surface, disabling the reverse self-repair reactions. This calls for processes in ambient conditions or at the solid-liquid interface. The formation of covalent bonds with thermodynamic control exploits their reversibility, enabling the dissociation and reconnection of molecular units which converge into the most thermodynamically stable structure. This is of great importance in driving specific biological reactions or self-repair of defects in polymeric networks leading to ordered organic layers.

Another possible strategy to obtain large ordered polymeric domains in the case of irreversible reactions is represented by the exploitation of intermediate states. Such states can be stable (e.g. the organometallic phase in the Ullmann coupling) or short-lived (transient states), which correspond to a local minimum in the potential energy curve of a given chemical reaction. Despite the overall reaction being irreversible, the reversible formation of transient states represents a key tool to control the ordering of the final polymeric layer (Section 4.3).

\subsection{Condensation of boronic acid derivatives}

The surface-confined condensation of boronic acid derivatives (Scheme 1) has been extensively investigated in vacuum as well as in ambient conditions, demonstrating the possibility to achieve high control over the reaction process and the final products by fine engineering of the precursor molecules [199]. 1,4-benzenediboronic acid precursors are used to form extended 2D COFs on HOPG: ex situ pre-synthesized small COFs are deposited on the substrate and a thermally induced ripening process leads to the formation of more extended ordered COFs. A similar final product is obtained by depositing the solution containing unreacted precursors on the HOPG by heating in a 
humid atmosphere: the presence of water during the thermal treatment facilitates the reversibility required for successful ordering at long-range [124]. This method has been further exploited by changing the structure of the precursor molecules, with the aim of tuning the geometry of the final 2D polymeric layer: pore dimensions are observed to increase from about 1.0 to $3.2 \mathrm{~nm}$ as a function of the precursor length (i.e. number of aromatic rings in between the two boronic acid functionalities) (Figure 7a) [125]. The reversibility of this process has been tested for biphenyldiboronic acid on HOPG showing good order and self-repair of defect for the 2D COFs. The regulation of the thermodynamic equilibrium for the covalent bond formation is driven by the presence of $\mathrm{CuSO}_{4} \cdot 5 \mathrm{H}_{2} \mathrm{O}$, increasing the partial pressure of water during the reaction and shifting the equilibrium backwards to favor the reverse reaction (hydrolysis) to a certain extent, thus improving self-adjustment of the molecules to form extended ordered $2 \mathrm{D}$ polymers (Figure $7 \mathrm{~b}$ ). It has been observed that these ordered networks can be damaged after storing in ambient condition for one week, but readily restored upon annealing [126].

Dehydration reactions have also been performed in UHV conditions, as in the case of 1,4benzenediboronic acid, forming 2D COFs on $\mathrm{Ag}(111)$. Pores with different dimensions can be obtained upon careful choice of the precursor molecules, demonstrating the control of the COF geometry, which is fundamental for further applications in the patterning of nano-arrays of magnetic, catalytic, or electronic devices [121]. In presence of a metal substrate acting as a catalyst, the reaction may proceed also at RT, yet lasting several tens of hours [122]. Interestingly, it has been shown on $\operatorname{Ag}(100)$ how the manipulation with the STM-tip or the exposure to an electron beam (15 eV for $20 \mathrm{~s})$ affect the kinetics of the transformation from the high-density $\mathrm{H}$-bonded phase to the low-density polymer phase, accelerating the process [122]. Mixed strategies can also be adopted: p-bromobenzene boronic acid has been found to dehydrate at RT on Au(111) in UHV, spontaneously condensing to trimers consisting of boroxine rings, which self-organize on the surface. In a second step, annealing of this structure to about $550 \mathrm{~K}$ enables the Ullmann-like coupling between the trimers (activating the halogenated sites of the molecules), producing a 2D COF [128].

Porous polymeric networks obtained by condensation of boronic acid derivatives have been used to host different molecules, such as fullerenes, demonstrating the sensing/trapping capability of the single layer COF, also revealing a simple synthesis route that can be applied to the fabrication of 2D donor/acceptor networks [123]. Additional manipulation of such multilayered structures can be achieved by local modifications using a STM-tip obtaining a sort of lithographic patterning: functional corrals may be obtained to host diverse molecular species (i.e. fullerenes, as shown in Figure 7c) [127]. 


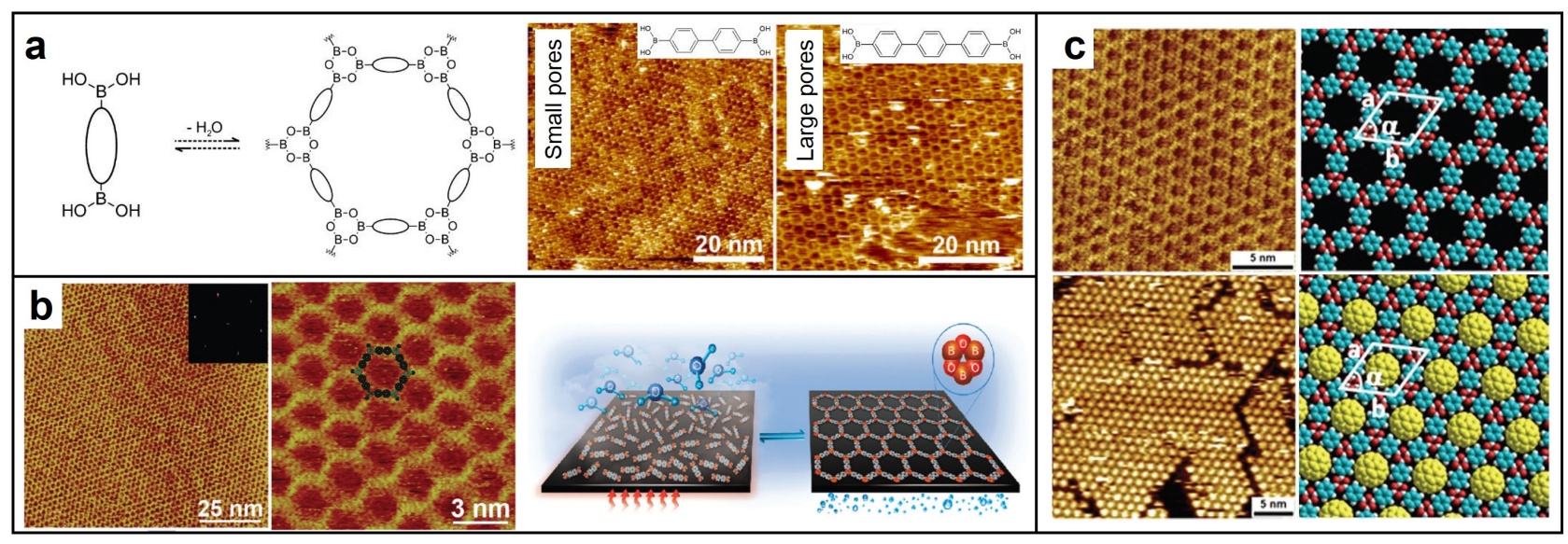

Figure 7. a: Formation of 2D polymers with different pore size from a boronic acid derivative precursor on HOPG in ambient conditions [125]. Adapted with permission from the American Chemical Society, copyright 2012. b: Water can be used in a close system to regulate the equilibrium of the 2D network formation [126]. Adapted with permission from the Royal Society of Chemistry, copyright 2011. c: The pores of a 2D network can be used to host different types of molecules, like fullerenes [127]. Adapted with permission from the Royal Society of Chemistry, copyright 2015.

\subsection{Schiff-base coupling}

The synthesis of imines through Schiff-base coupling is another chemical reaction that can undergo thermodynamic equilibrium showing a reversibility of the covalent bond formation (Scheme 1). The imine linkage has been largely investigated in traditional synthetic chemistry, unveiling the mechanisms driving its formation and the importance of its activity in biological systems [200-202]. Imines can participate in three types of equilibrium-controlled reactions: (i) hydrolysis, (ii) transimination and (iii) imine-imine exchange [203].

The on-surface reversibility of the imine bond formed upon Schiff-base coupling has been investigated and directly visualized by STM. This approach demonstrates the possibility of merging the error-correction capacity derived from supramolecular chemistry and the robustness typical of covalently-linked structures [135]. Formation of trimers from 4-(hexadecyloxy)benzaldehyde and diamines with different length has been studied on HOPG immersed in 1-phenyloctane/pyridine solution, demonstrating the possibility of replacing the central molecular unit (diamine) with a longer one (by transimination) (Figure 8a). The process turns out to be driven by the free-energy of physisorption: longer chains are more stable than shorter ones and they are preferentially selected from the dynamic library present in solution. Performing the reverse transimination (back to shorter chains) is partly possible after longer reaction time and upon drastic change of the reaction 
conditions (molecular concentration). The HOPG surface has two main effects: it completes the reaction and selects specific constituents from the solution.

The use of Schiff-base coupling to covalently link organic building blocks on surfaces was first demonstrated in UHV conditions synthesizing small molecules like bisimines [133] and trisimines [132] at RT which then self-organize with long-range order on the Au(111) surface. Annealing the molecular surface structures at 400-450 K led to larger domains of bisimines. Different deposition conditions of the precursors (amine flux and substrate temperature) produce compact or porous selfassembled networks of the condensed products, both different from the ex situ synthesized product deposited on the surface, demonstrating that the on-surface synthesis allows the formation of unique structures not obtainable through other methods.

The formation of bisimines has also been spectroscopically investigated for the coupling between pentafluorobenzaldehyde and 4,4'-methylenebis(2,6-diethylaniline) in a toluene solution on silicon wafers: the imine formation has been demonstrated by XPS and NEXAFS spectroscopies before and after the reaction, providing one of the few spectroscopic investigations on the formation of Schiff-bases on surfaces [134].

Other works reporting the formation of small oligomers are present in the literature, such as the case of self-assembled layers of melamine on HOPG exposed to vapors of molecules containing aldehyde groups, performing Schiff-base coupling in ambient conditions upon thermal treatment. This method produces small imine oligomers self-organized on the surface with different geometries according to the shape of the precursors [150]. More promising are the results obtained using different precursors to form 2D COFs on HOPG with different pore sizes at the solid-vapor interface. The surface, pre-loaded with one of the two precursors by drop-casting, has been introduced into a reactor in the presence of the other precursor molecules and $\mathrm{CuSO}_{4} \cdot 5 \mathrm{H}_{2} \mathrm{O}$ as a thermodynamic regulation agent. At suitable temperatures, the condensation occurs and ordered polymeric networks are obtained (Figure 8b) [151]. A similar approach, depositing the precursor molecules in a tetrahydrofuran solution on HOPG, has been successfully adopted to form 1D and 2D polymers with different shape by changing the amines and aldehydes used as reactants, as shown in Figure 8c [136].

Short disordered oligomers have been obtained in the co-presence of melamine islands at the solidliquid interface between $\mathrm{Au}(111)$ and dimethylformamide by mixing melamine and terephthalaldehyde, with the melamine islands disappearing over time (approximately in 48 hours) [137]. On the other hand, a certain degree of ordering of longer oligomeric structures has been achieved on HOPG [138-139]. 
Precursor molecules with different lengths bearing two amino units have been coupled with 1,3,5tricarbaldehyde to obtain 2D polymers at the interface between octanoic acid and HOPG, with particular attention to the structural changes and defects in the extended COF layers [145]. One of these molecular couples has also been studied on a single-layer graphene grown on a copper substrate, immersed in octanoic acid. A morphological investigation of the layer obtained revealed " $5+7$ " defects, similar to the Stone-Wales defects observed for graphene, implying a strong coupling between the COF and the underlying graphene [146]. The effect of different side functionalization $\left(\mathrm{OH}\right.$ or $\left.\mathrm{OCH}_{3}\right)$ of the precursor molecules on the final polymeric structure has also been investigated for similar systems [147]. Porphyrin-based precursors have been used, in analogy with the previous studies, and DFT calculations on the final 2D polymers reveal the semiconductor character of such layers [148].

Distinct isomeric routes have been explored in the formation of imine-linked COFs: placing amino and aldehyde groups in tri- and bifunctional monomers and vice versa allows the effect of monomer structure on the growth to be understood. The behavior of the final $2 \mathrm{D}$ polymers obtained via Schiff-base coupling at the interface between tetrahydrofuran and HOPG closely resembles that of the different trifunctional precursors, demonstrating that the mobility, affected by the presence of different substituents in the molecule, plays a key role in the organization of the self-assembled structure and of the 2D COFs. The temperature influences on the final structure has also been investigated: multi-walled porous structures or ordered honeycomb networks can be obtained as a function of increasing temperature [144]. A similar approach has been adopted to obtain 2D polymers with non-aromatic linkage, demonstrating that the high conformation flexibility, high surface mobility, and high reactivity of non-aromatic precursors contribute to the formation of more defective structures compared to the aromatic linkage [149]. 


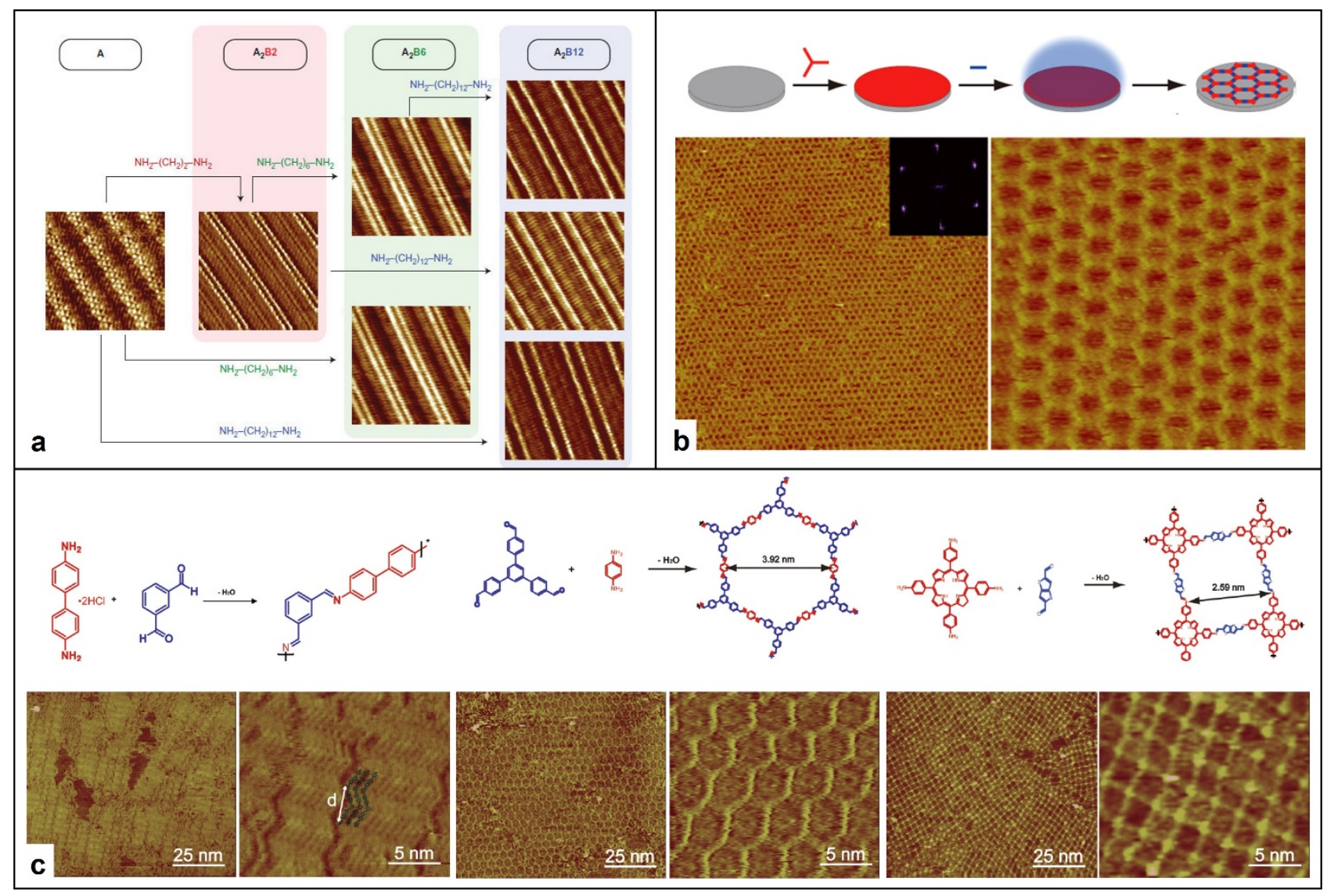

Figure 8. a: The reversibility of Schiff-base coupling has been demonstrated by replacement of the central unit of a trimer with units of increasing length, as imaged by in situ STM [135]. Adapted with permission from Nature Publishing Group, copyright 2014. b: Schiff-base coupling of two precursors: the first is deposited on a HOPG surface and the second is added as a vapor, leading to the formation of 2D polymers [151]. Adapted with permission from the American Chemical Society, copyright 2015. c: The final geometry of a polymeric network obtained via Schiff-base coupling can be precisely designed by careful choice of the precursor monomers [136]. Adapted with permission from AIP Publishing LLC, copyright 2015.

In all the examples of surface-confined Schiff-base coupling reported above, the reactions were conducted either in ambient conditions or at the interface between a solid substrate and an organic solvent. In fact, the precursor molecules usually adopted in these experiments are soluble in nonpolar solvents. However, the use of aqueous solution has also been reported, as an inexpensive and sustainable route to obtain $1 \mathrm{D}$ and $2 \mathrm{D} \pi$-conjugated polymers on surfaces that could be extended to large-scale production. Processes occurring in water enable the control of the reaction evolution through the $\mathrm{pH}$ and may be extended to application in biology and medicine.

A series of $1 \mathrm{D}$ and 2D polymers have been obtained at the interface between iodine-modified $\mathrm{Au}(111)$ and water upon Schiff-base coupling of several precursors (Figure 9a), revealing the dynamic character of the bonds observed by in situ STM, the presence of polymeric adlayers beyond the first, the weak physisorption character of such polymers and the positional selectivity of 
the condensation reaction [141-143]. However, these works report only on the final polymeric structure. We have focused on the details of the Schiff-base coupling at the solid-water interface especially referring to the $\mathrm{pH}$ control by the use of microscopic and spectroscopic investigation [140]. All the reaction steps on iodine-modified $\mathrm{Au}(111)$ have been monitored by XPS measurements, showing that both intermediate (previously observed only in bulk solution) [204206] and $\pi$-conjugated polymers, undistinguishable by STM, are on the surface (Figure 9b). Their ratio progressively changes with increasing $\mathrm{pH}$, in favor of $\pi$-conjugated polymers. It has been shown that the surface enhances the polymer production, compared to the bulk solution, because of the densification of the molecules at the hydrophobic I/Au(111) surface and because of the interplay between solvation and adsorption of the molecules bearing the amine functionalities [140].

The enhancement observed on the $\mathrm{I} / \mathrm{Au}(111)$ surface is fundamental in terms of large scale production of imine-based polymers, since at suitable $\mathrm{pH}$ values of the aqueous solution it allows the synthesis of the polymeric network only at the surface, leaving the solution nearly unaltered and ready to be used with other substrates. However, such enhancement occurs if the interaction between the precursor molecules and the substrate is significant, and this contrasts the diffusion of the molecules on the surface, which is the key aspect to obtain ordered structures extending over the whole polymeric domain. Therefore, a careful choice of the molecules and surface is needed to finely balance the interactions between these two actors.

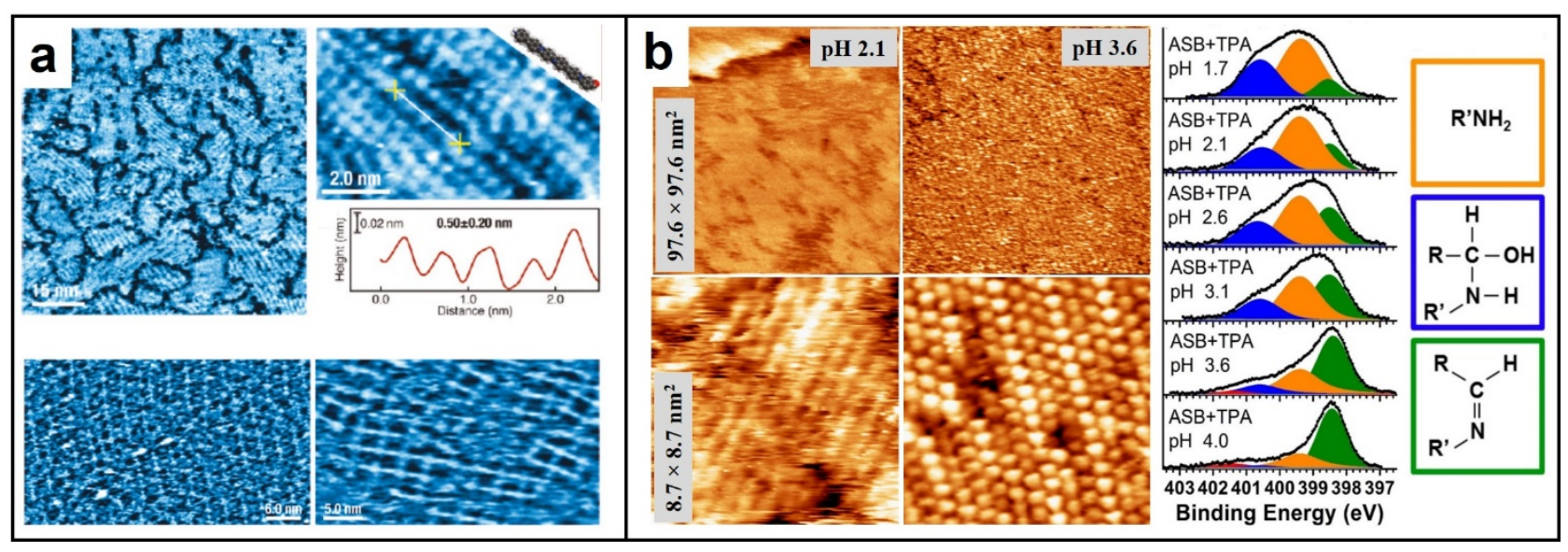

Figure 9. a: STM images of $1 D$ and $2 D$ polymers formed at the interface between $A u(111)$ and water via Schiff-base coupling [141]. Adapted with permission from the American Chemical Society, copyright 2011. b: XPS investigation of the system allows the chemical transformation taking place to be unveiled at the solid-liquid interface, showing all the chemical states corresponding to the different steps of the Schiff-base coupling: intact precursors, intermediate nonconjugated polymers and final $\pi$-conjugated polymers (the last two being undistinguishable by STM) [140]. Adapted with permission from the American Chemical Society, copyright 2015. 


\subsection{Exploiting intermediate states}

Most of the strategies typically adopted when dealing with surface-confined polymerization make use of irreversible coupling reactions. In this case the advantages of self-correction of errors in the molecular superstructures, typical of reversible reactions, are lost. However, in some irreversible polymerization reactions the covalent coupling is preceded by intermediate steps which can be stable or short-living, and can be exploited to increase the final ordered domains.

The most prominent example is Ullmann coupling. In this two-step reaction the halogens detach from the precursor and the resulting radicals bind the metal catalyst (copper) forming a stable organometallic phase. Afterwards, the $\mathrm{C}-\mathrm{C}$ bond formation takes place. In general, every metal catalyzed dehalogenative coupling follows this reaction pathway. However, the rate-limiting step of the overall process can differ according to the specific molecule/substrate combination. If the dehalogenation is the rate-limiting step, the polymerization will occur as soon as the halogens are removed, without any possibility of controlling the process. On the other hand, if the C-C coupling is the rate-limiting step, the intermediate phase will be stable in a certain temperature range and it will be possible to design a suitable reaction path which makes use of this intermediate to improve the quality of the final polymeric phase.

This concept was already present in the literature concerning the hierarchical growth of $1 \mathrm{D}$ and 2D porphyrin-based polymers [89], where the order of the final polymeric structure can be increased by introducing an additional intermediate step in the reaction. Since different halogens have different temperatures of dissociation from the carbon atoms, a hierarchical polymer growth on surfaces can be achieved for monomers containing different halogens. This has been observed in a two-step synthetic process for 5,15-bis(4'-bromophenyl)-10,20-bis(4'-iodophenyl)porphyrin adsorbed on $\mathrm{Au}(111)$ and $\mathrm{Au}(100)$ (Figure 10a). In the first step iodine atoms are removed from the precursors by annealing the surface at $390 \mathrm{~K}$, activating two opposite sites in each molecule and leading to the formation of $1 \mathrm{D}$ covalent polymers. In the second step, occurring at $520 \mathrm{~K}$, bromine atoms are removed and the pre-synthesized chains are linked together in a 2D covalent network. If a precursor molecule with the same halogen atoms at the four active sites is used (5,10,15,20-tetrakis(4'bromophenyl)porphyrin), the same final geometry of the polymer is obtained, but with reduced order. This demonstrates that the introduction of stable intermediate states of self-assembly of 1D polymeric chains (adopting the procedure based on hierarchical growth) increases the size of the $2 \mathrm{D}$ polymeric domains [89]. Moreover, organometallic intermediates in Ullmann-like coupling 
reactions are able to facilitate the conformational selectivity of specific products, as observed in the formation of porous GNRs from 1,3,5-tris(3-bromophenyl)benzene on $\mathrm{Ag}(111)$ [112].

Beyond the control of stable intermediate phases, also the presence of short-lived states plays a crucial role in the final order of the polymer. This aspect has been addressed by a few works [102, 207-208], where Monte Carlo simulations are compared to STM experiments of various polymeric networks on different surfaces. In these simulations a seed molecule is placed in a fixed position on a surface and other molecules can randomly walk until they sit on a site adjacent to the seed (reactive site), where they can either couple to the seed (irreversible process) or back-diffuse. The coupling probability is defined as:

$P=\frac{v_{c}}{v_{c}+v_{d}}$

where $v_{c}$ and $v_{d}$ are the probabilities per unit time of the two complementary processes (coupling and back-diffusion, respectively). Monte Carlo simulations show that for $\mathrm{P} \sim 1$ (coupling is the more favorable mechanism) fractal-like polymeric structures are obtained, while for $\mathrm{P} \ll 1$ (monomers are more likely to diffuse away from the reactive site) long-range ordered domains are formed on the surface. These simulations qualitatively match the morphologies of polymers experimentally observed by STM, obtained upon molecular adsorption on three different substrates $(\mathrm{Cu}(111)$, $\mathrm{Au}(111)$ and $\mathrm{Ag}(111)$ ) followed by covalent bond formation at $475 \mathrm{~K}, 525 \mathrm{~K}$ and $575 \mathrm{~K}$, respectively, with the aim of changing the probability for coupling and back-diffusion [102]. Such agreement between simulations and experiments indicates that the adopted model is able to capture salient features of Ullmann polymerization (Figure 10b). This approach, based on the coupling probability, implies the presence of a short-lived (transient) state in the polymerization reaction, as recently reported [97]. The presence of a transient state can therefore be exploited to improve the extension of ordered domains.

In this framework, we have proposed a kinetic model for the Ullmann coupling of 1,4dibromobenzene on $\mathrm{Cu}(110)$, based on mean field rate equations, that describes the experimental kinetic curves derived from fast-XPS measurements [97]. In this model, we take into account the main processes occurring during the coupling reaction, including a transient state (Figure 10c). This state is observed in the energy landscapes calculated by nudged elastic band (NEB) within DFT, which assumes as initial and final geometries of the organometallic structure and the polymeric product those observed by STM (Figure 10d). The kinetic model accounts for all the salient features observed in the experimental curves extracted from the fast-XPS measurements and enables an enhanced understanding of the polymerization process that is found to follow a nucleation-andgrowth behavior preceded by the formation of a transient state (Figure 10e). The growth of a polymer from an existing nucleus (dimer) requires substantially less energy than creating the 
nucleus out of the stable RT phase. The experimental fast-XPS data is most accurately described by a scenario where the coupling probability between the monomers is low, in agreement with STM observations of domains composed of long polymers [97]. This methodology can be applied to other systems/reactions for a better understanding of the mechanisms of surface-confined processes.

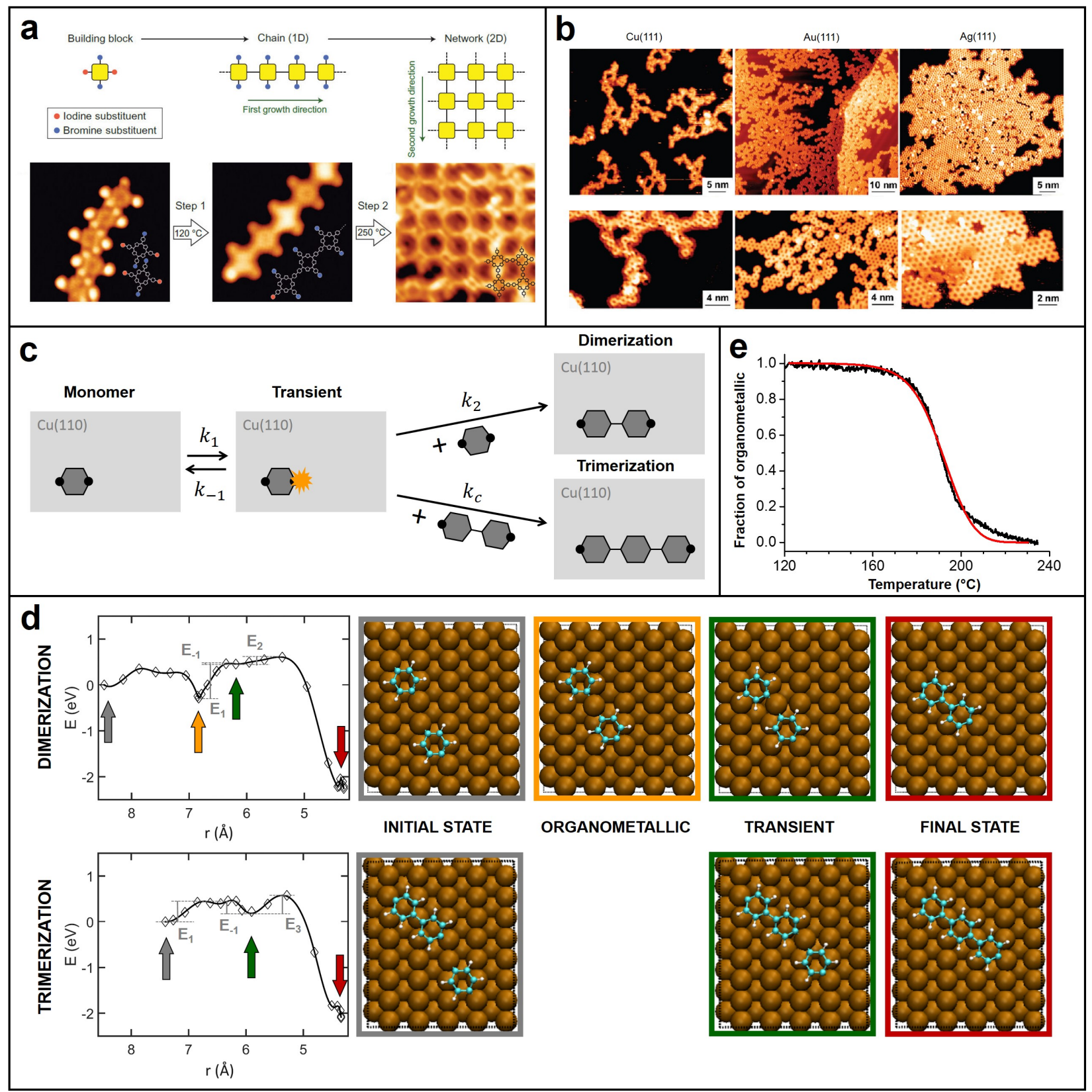

Figure 10. a: Hierarchical growth obtained via Ullmann-like coupling according to a sequential thermal activation of porphyrin-based molecular precursors. 1D or 2D polymers are formed at different annealing temperatures [89]. Adapted with permission from Nature Publishing Group, copyright 2012. b: Polyphenylene networks formed on Cu(111), $\mathrm{Au}(111)$, and $\operatorname{Ag}(111)$, showing that the competition of coupling and diffusion barriers (here modified by using different substrates) is fundamental to drive the geometry of the final polymers [102]. Adapted with permission from the American Chemical Society, copyright 2010. c: Sketch of a coupling reaction involving the presence of a transient species (see the original article for the corresponding kinetic equations) [97]. d: Potential energy curves for the coupling 
between two monomers (dimerization) and a monomer and a dimer (trimerization) calculated by DFT. The corresponding geometries along the reaction paths are reported in the colored frames [97]. e: Fit (red curve) of an experimental kinetic curve (black curve) obtained for the surface-confined polymerization of 1,4-dibromobenzene on $\mathrm{Cu}(110)$. The good agreement confirms that a model assuming the presence of a transient species is representative of the coupling mechanism [97]. c-e: Adapted with permission from the American Chemical Society, copyright 2016.

The examples reported in this section show that the control of the intermediate states of a coupling reaction is a crucial aspect in view of optimizing the quality (order and extension) of the final polymeric layer. The use of different molecule/substrate configurations together with the engineering of the precursor molecules with suitable substituent groups enable the possibility of changing the potential energy curves describing the polymerization process to improve the morphology and the properties of a given polymeric layer, with unprecedented results in terms of fine tuning the growth process.

\section{Conclusions}

The works on surface-confined polymerization reported here show that several methods can be adopted to synthesize ordered low-dimensional organic nanostructures with tunable characteristics, with great potential for future applications. Almost two decades of studies on these reactions have shed light on this world at the border between physics and chemistry, demonstrating the feasibility of several synthetic methods and promoting the investigation of new, still unexplored, routes. However, a clear and full understanding of the reaction mechanisms leading to the polymerization is not always achieved. Great attention is often given to the final polymeric structure, while the investigation of the reaction intermediates, leading to a specific geometry, becomes marginal. In particular, more efforts are needed to better explore the pathways regarding the growth on insulators, the use of reversible reactions, and the exploitation of intermediate reaction steps in order to obtain long-range ordered covalent organic networks that can be included in real-life devices. In this review, we have underlined some studies involving reversible coupling reactions, such as the condensation of boronic acids and Schiff-base coupling, showing that these dehydration processes can be exploited to obtain a great variety of moieties in less demanding reaction conditions compared to UHV-based methods, being also good candidates for large-scale production. We have also stressed the importance of intermediate steps (both stable and short-lived) as key ingredients to improve the order of the final polymeric layer in the case of irreversible pathways, which are the most frequently used reactions. The insights provided in this work 
highlight features enabling a fine tuning of the growth conditions of surface-confined polymeric networks, to be used in the fabrication of real-life devices.

\section{References}

[1] Crommie, M. F.; Lutz, C. P.; Eigler, D. M. 1993, Science 262, 218-220.

[2] Eigler, D. M.; Schweizer, E. K. 1990, Nature 344, 524-526.

[3] Jung, T. A.; Schlittler, R. R.; Gimzewski, J. K.; Tang, H.; Joachim, C. 1996, Science 271, 181-184.

[4] Flood, A. H.; Stoddart, J. F.; Steuerman, D. W.; Heath, J. R. 2004, Science 306, 2055-2056.

[5] Joachim, C.; Gimzewski, J. K.; Aviram, A. 2000, Nature 408, 541-548.

[6] Song, H.; Reed, M. A.; Lee, T. 2011, Adv. Mater. 23, 1583-1608.

[7] Cuevas, J. C.; Scheer, E., Molecular Electronics - An Introduction to Theory and Experiment. World Scientific: Singapore, 2010.

[8] Palma, C.-A.; Samorì, P. 2011, Nat. Chem. 3, 431-436.

[9] Novoselov, K. S.; Geim, A. K.; Morozov, S. V.; Jiang, D.; Zhang, Y.; Dubonos, S. V.; Grigorieva, I. V.; Firsov, A. A. 2004, Science 306, 666-669.

[10] Ferrari, A. C.; Bonaccorso, F.; Fal'ko, V.; Novoselov, K. S.; Roche, S.; Boggild, P.; Borini, S.; Koppens, F. H. L.; Palermo, V.; Pugno, N.; et al. 2015, Nanoscale 7, 4598-4810.

[11] Hatanaka, M. 2010, Chem. Phys. Lett. 488, 187-192.

[12] Gutzler, R.; Perepichka, D. F. 2013, J. Am. Chem. Soc. 135, 16585-16594.

[13] Balog, R.; Jorgensen, B.; Nilsson, L.; Andersen, M.; Rienks, E.; Bianchi, M.; Fanetti, M.; Laegsgaard, E.; Baraldi, A.; Lizzit, S.; et al. 2010, Nat. Mater. 9, 315-319.

[14] Zbořil, R.; Karlický, F.; Bourlinos, A. B.; Steriotis, T. A.; Stubos, A. K.; Georgakilas, V.; Šafářová, K.; Jančík, D.; Trapalis, C.; Otyepka, M. 2010, Small 6, 2885-2891.

[15] Zhu, C.; Yang, G. 2016, Chem. Phys. Chem. 17, 2482-2488.

[16] Tapaszto, L.; Dobrik, G.; Lambin, P.; Biro, L. P. 2008, Nat. Nano. 3, 397-401.

[17] Gourdon, A., On-Surface Synthesis: Proceedings of the International Workshop On-Surface Synthesis, École des Houches, Les Houches 25-30 May 2014. Springer International Publishing: 2016.

[18] Lackinger, M. 2015, Polym. Int. 64, 1073-1078.

[19] Lindner, R.; Kühnle, A. 2015, Chem. Phys. Chem. 16, 1582-1592.

[20] Lehn, J.-M., Supramolecular Chemistry: Concept and Perspectives. VCH, Weinheim, 1995.

[21] Reinhoudt, D. N.; Crego-Calama, M. 2002, Science 295, 2403-2407.

[22] Barth, J. V. 2007, Annu. Rev. Phys. Chem. 58, 375-407.

[23] Ciesielski, A.; Palma, C.-A.; Bonini, M.; Samorì, P. 2010, Adv. Mater. 22, 3506-3520.

[24] Barth, J. V.; Costantini, G.; Kern, K. 2005, Nature 437, 671-679.

[25] Bonifazi, D.; Mohnani, S.; Llanes-Pallas, A. 2009, Chem. - Eur. J. 15, 7004-7025.

[26] De Feyter, S.; De Schryver, F. C. 2003, Chem. Soc. Rev. 32, 139-150.

[27] Elemans, J. A. A. W.; Lei, S.; De Feyter, S. 2009, Angew. Chem. Int. Edit. 48, 7298-7332.

[28] Gallego, J. M.; Otero, R.; Miranda, R., The Growth of Organic Nanomaterials by Molecular SelfAssembly at Solid Surfaces. In Organic Nanomaterials, John Wiley \& Sons, Inc.: 2013; pp 421-446.

[29] Gutzler, R.; Cardenas, L.; Rosei, F. 2011, Chem. Sci. 2, 2290-2300.

[30] Otero, R.; Gallego, J. M.; de Parga, A. L. V.; Martín, N.; Miranda, R. 2011, Adv. Mater. 23, 51485176.

[31] Otero, R.; Rosei, F.; Besenbacher, F. 2006, Annu. Rev. Phys. Chem. 57, 497-525.

[32] Zhang, S. 2003, Nat. Biotech. 21, 1171-1178.

[33] Allegretti, F.; De Renzi, V.; Biagi, R.; del Pennino, U.; Contini, G.; Di Castro, V.; Mariani, C.; Betti, M. G.; Fontanesi, C. 2003, Surf. Sci. 539, 63-71.

[34] Carravetta, V.; Contini, G.; Plashkevych, O.; Ågren, H.; Polzonetti, G. 1999, J. Phys. Chem. A 103, 4641-4648. 
[35] Contini, G.; Laajalehto, K.; Suoninen, E.; Marabini, A. M. 1995, J. Colloid Interface Sci. 171, 234239.

[36] Di Castro, V.; Allegretti, F.; Baldacchini, C.; Grazia Betti, M.; Contini, G.; Corradini, V.; Lamastra, F.; Mariani, C. 2002, Surf. Sci. 507, 7-11.

[37] Gori, P.; Contini, G.; Prosperi, T.; Catone, D.; Turchini, S.; Zema, N.; Palma, A. 2008, J. Phys. Chem. B 112, 3963-3970.

[38] Lipton-Duffin, J.; Miwa, J. A.; Urquhart, S. G.; Contini, G.; Cossaro, A.; Casalis, L.; Barth, J. V.; Floreano, L.; Morgante, A.; Rosei, F. 2012, Langmuir 28, 14291-14300.

[39] Polzonetti, G.; Carravetta, V.; Russo, M. V.; Contini, G.; Parent, P.; Laffon, C. 1999, J. Electron. Spectrosc. Relat. Phenom. 98, 175-187.

[40] Urgel, J. I.; Ecija, D.; Auwärter, W.; Stassen, D.; Bonifazi, D.; Barth, J. V. 2015, Angew. Chem. Int. Edit. 54, 6163-6167.

[41] Urgel, J. I.; Écija, D.; Lyu, G.; Zhang, R.; Palma, C.-A.; Auwärter, W.; Lin, N.; Barth, J. V. 2016, Nat. Chem. 8, 657-662.

[42] Otero, R.; Schöck, M.; Molina, L. M.; Lægsgaard, E.; Stensgaard, I.; Hammer, B.; Besenbacher, F. 2005, Angew. Chem. Int. Edit. 44, 2270-2275.

[43] Barth, J. V.; Weckesser, J.; Cai, C.; Günter, P.; Bürgi, L.; Jeandupeux, O.; Kern, K. 2000, Angew. Chem. Int. Edit. 39, 1230-1234.

[44] MacLeod, J. M.; Lipton-Duffin, J. A.; Cui, D.; De Feyter, S.; Rosei, F. 2015, Langmuir 31, 70167024.

[45] Contini, G.; Gori, P.; Di Giovannantonio, M.; Zema, N.; Turchini, S.; Catone, D.; Prosperi, T.; Palma, A. 2013, J. Phys. Chem. C 117, 10545-10551.

[46] Abdel-Mottaleb, M. M. S.; Gomar-Nadal, E.; Surin, M.; Uji-i, H.; Mamdouh, W.; Veciana, J.; Lemaur, V.; Rovira, C.; Cornil, J.; Lazzaroni, R.; et al. 2005, J. Mater. Chem. 15, 4601-4615.

[47] Yokoyama, T.; Yokoyama, S.; Kamikado, T.; Okuno, Y.; Mashiko, S. 2001, Nature 413, 619-621.

[48] Ernst, K.-H. 2012, Phys. Status Solidi B 249, 2057-2088.

[49] Raval, R. 2009, Chem. Soc. Rev. 38, 707-721.

[50] Contini, G.; Gori, P.; Ronci, F.; Zema, N.; Colonna, S.; Aschi, M.; Palma, A.; Turchini, S.; Catone, D.; Cricenti, A.; et al. 2011, Langmuir 27, 7410-7418.

[51] De Feyter, S.; De Schryver, F. C. 2005, J. Phys. chem. B 109, 4290-4302.

[52] Irrera, S.; Contini, G.; Zema, N.; Turchini, S.; Fujii, J.; Sanna, S.; Prosperi, T. 2007, J. Phys. Chem. B 111, 7478-7480.

[53] Irrera, S.; Contini, G.; Zema, N.; Turchini, S.; Sanna, S.; Moras, P.; Crotti, C.; Prosperi, T. 2007, Surf. Sci. 601, 2562-2565.

[54] Perez-Garcia, L.; Amabilino, D. B. 2007, Chem. Soc. Rev. 36, 941-967.

[55] Contini, G.; Turchini, S.; Sanna, S.; Catone, D.; Fujii, J.; Vobornik, I.; Prosperi, T.; Zema, N. 2012 , Phys. Rev. B 86, 035426.

[56] Parschau, M.; Kampen, T.; Ernst, K.-H. 2005, Chem. Phys. Lett. 407, 433-437.

[57] Haq, S.; Liu, N.; Humblot, V.; Jansen, A. P. J.; Raval, R. 2009, Nat. Chem. 1, 409-414.

[58] Fasel, R.; Parschau, M.; Ernst, K.-H. 2006, Nature 439, 449-452.

[59] Lackinger, M.; Griessl, S.; Heckl, W. M.; Hietschold, M.; Flynn, G. W. 2005, Langmuir 21, 49844988.

[60] MacLeod, J. M.; Ivasenko, O.; Fu, C.; Taerum, T.; Rosei, F.; Perepichka, D. F. 2009, Journal of the American Chemical Society 131, 16844-16850.

[61] Uemura, S.; Aono, M.; Sakata, K.; Komatsu, T.; Kunitake, M. 2013, J. Phys. Chem. C 117, $24815-$ 24821.

[62] Palma, C.-A.; Bjork, J.; Bonini, M.; Dyer, M. S.; Llanes-Pallas, A.; Bonifazi, D.; Persson, M.; Samorì, P. 2009, J. Am. Chem. Soc. 131, 13062-13071.

[63] Lehn, J.-M. 2007, Chem. Soc. Rev. 36, 151-160.

[64] Lehn, J.-M. 1988, Angew. Chem. Int. Edit. Engl. 27, 89-112.

[65] Lehn, J.-M. 2002, Proc. Natl. Acad. Sci. U.S.A. 99, 4763-4768.

[66] Bartels, L. 2010, Nat. Chem. 2, 87-95.

[67] Gourdon, A. 2008, Angew. Chem. Int. Edit. 47, 6950-6953.

[68] Heath J. R.; Ratner M. A. 2003, Phys. Today 56, 43-49.

[69] Hecht, S. 2003, Angew. Chem. Int. Edit. 42, 24-26.

[70] Perepichka, D. F.; Rosei, F. 2009, Science 323, 216-217. 
[71] Chiang, C. K.; Fincher, C. R.; Park, Y. W.; Heeger, A. J.; Shirakawa, H.; Louis, E. J.; Gau, S. C.; MacDiarmid, A. G. 1977, Phys. Rev. Lett. 39, 1098-1101.

[72] Skotheim, T. A.; Reynolds, J. R., Conjugated Polymers: Theory, Synthesis, Properties, and Characterization. CRC Press: 2007.

[73] Cooper, A. I. 2009, Adv. Mater. 21, 1291-1295.

[74] Champness, N. R. 2007, Nat. Nano. 2, 671-672.

[75] Ferrari, A. C.; Bonaccorso, F.; Fal'Ko, V.; Novoselov, K. S.; Roche, S.; Bøggild, P.; Borini, S.; Koppens, F. H.; Palermo, V.; Pugno, N. 2015, Nanoscale 7, 4598-4810.

[76] Franc, G.; Gourdon, A. 2011, Phys. Chem. Chem. Phys. 13, 14283-14292.

[77] Sakamoto, J.; van Heijst, J.; Lukin, O.; Schlüter, A. D. 2009, Angew. Chem. Int. Edit. 48, 1030-1069.

[78] Lackinger, M.; Heckl, W. M. 2011, J. Phys. D Appl. Phys. 44, 464011.

[79] Mendez, J.; Lopez, M. F.; Martin-Gago, J. A. 2011, Chem. Soc. Rev. 40, 4578-4590.

[80] Liu, X.-H.; Guan, C.-Z.; Wang, D.; Wan, L.-J. 2014, Adv. Mater. 26, 6912-6920.

[81] Zhuang, X.; Mai, Y.; Wu, D.; Zhang, F.; Feng, X. 2014, Adv. Mater. 27, 403-427.

[82] Lackinger, M. 2017, Chem. Commun. 53, 7872-7885.

[83] Zint, S.; Ebeling, D.; Schlöder, T.; Ahles, S.; Mollenhauer, D.; Wegner, H. A.; Schirmeisen, A. 2017, ACS Nano 11, 4183-4190.

[84] Lewis, E. A.; Marcinkowski, M. D.; Murphy, C. J.; Liriano, M. L.; Therrien, A. J.; Pronschinske, A.; Sykes, E. C. H. 2017, Chem. Commun. 53, 7816-7819.

[85] Grill, L.; Dyer, M.; Lafferentz, L.; Persson, M.; Peters, M. V.; Hecht, S. 2007, Nat. Nano. 2, 687-691.

[86] Adisoejoso, J.; Lin, T.; Shang, X. S.; Shi, K. J.; Gupta, A.; Liu, P. N.; Lin, N. 2014, Chem. - Eur. J. 20, 4111-4116.

[87] Bombis, C.; Ample, F.; Lafferentz, L.; Yu, H.; Hecht, S.; Joachim, C.; Grill, L. 2009, Angew. Chem. Int. Edit. 48, 9966-9970.

[88] Lafferentz, L.; Ample, F.; Yu, H.; Hecht, S.; Joachim, C.; Grill, L. 2009, Science 323, 1193-1 197.

[89] Lafferentz, L.; Eberhardt, V.; Dri, C.; Africh, C.; Comelli, G.; Esch, F.; Hecht, S.; Grill, L. 2012, Nat. Chem. 4, 215-220.

[90] Lin, T.; Shang, X. S.; Adisoejoso, J.; Liu, P. N.; Lin, N. 2013, J. Am. Chem. Soc. 135, 3576-3582.

[91] Schlütter, F.; Rossel, F.; Kivala, M.; Enkelmann, V.; Gisselbrecht, J.-P.; Ruffieux, P.; Fasel, R.; Müllen, K. 2013, J. Am. Chem. Soc. 135, 4550-4557.

[92] Wang, W.; Shi, X.; Wang, S.; Van Hove, M. A.; Lin, N. 2011, J. Am. Chem. Soc. 133, 13264-13267.

[93] Di Giovannantonio, M.; El Garah, M.; Lipton-Duffin, J.; Meunier, V.; Cardenas, L.; Fagot Revurat, Y.; Cossaro, A.; Verdini, A.; Perepichka, D. F.; Rosei, F.; et al. 2013, ACS Nano 7, 8190-8198.

[94] Lipton-Duffin, J. A.; Ivasenko, O.; Perepichka, D. F.; Rosei, F. 2009, Small 5, 592-597.

[95] Lipton-Duffin, J. A.; Miwa, J. A.; Kondratenko, M.; Cicoira, F.; Sumpter, B. G.; Meunier, V.; Perepichka, D. F.; Rosei, F. 2010, Proc. Natl. Acad. Sci. U.S.A. 107, 11200-11204.

[96] Vasseur, G.; Fagot-Revurat, Y.; Sicot, M.; Kierren, B.; Moreau, L.; Malterre, D.; Cardenas, L.; Galeotti, G.; Lipton-Duffin, J.; Rosei, F.; et al. 2016, Nat. Commun. 7, 10235.

[97] Di Giovannantonio, M.; Tomellini, M.; Lipton-Duffin, J.; Galeotti, G.; Ebrahimi, M.; Cossaro, A.; Verdini, A.; Kharche, N.; Meunier, V.; Vasseur, G.; et al. 2016, J. Am. Chem. Soc. 138, 16696-16702.

[98] Galeotti, G.; Di Giovannantonio, M.; Lipton-Duffin, J.; Ebrahimi, M.; Tebi, S.; Verdini, A.; Floreano, L.; Fagot-Revurat, Y.; Perepichka, D.; Rosei, F.; et al. 2017, Faraday Discuss. Accepted manuscript.

[99] Kittelmann, M.; Nimmrich, M.; Lindner, R.; Gourdon, A.; Kühnle, A. 2013, ACS Nano 7, 5614-5620.

[100] Kolmer, M.; Ahmad Zebari, A. A.; Prauzner-Bechcicki, J. S.; Piskorz, W.; Zasada, F.; Godlewski, S.; Such, B.; Sojka, Z.; Szymonski, M. 2013, Angew. Chem. Int. Edit. 52, 10300-10303.

[101] Kolmer, M.; Zuzak, R.; Ahmad Zebari, A. A.; Godlewski, S.; Prauzner-Bechcicki, J. S.; Piskorz, W.; Zasada, F.; Sojka, Z.; Bleger, D.; Hecht, S.; et al. 2015, Chem. Commun. 51, 11276-11279.

[102] Bieri, M.; Nguyen, M.-T.; Groning, O.; Cai, J.; Treier, M.; Ait-Mansour, K.; Ruffieux, P.; Pignedoli, C. A.; Passerone, D.; Kastler, M.; et al. 2010, J. Am. Chem. Soc. 132, 16669-16676.

[103] Blunt, M. O.; Russell, J. C.; Champness, N. R.; Beton, P. H. 2010, Chem. Commun. 46, 7157-7159.

[104] Gutzler, R.; Walch, H.; Eder, G.; Kloft, S.; Heckl, W. M.; Lackinger, M. 2009, Chem. Commun. 44564458.

[105] Bieri, M.; Treier, M.; Cai, J.; Ait-Mansour, K.; Ruffieux, P.; Groning, O.; Groning, P.; Kastler, M.; Rieger, R.; Feng, X.; et al. 2009, Chem. Commun. 6919-6921.

[106] Cardenas, L.; Gutzler, R.; Lipton-Duffin, J.; Fu, C.; Brusso, J. L.; Dinca, L. E.; Vondracek, M.; FagotRevurat, Y.; Malterre, D.; Rosei, F.; et al. 2013, Chem. Sci. 4, 3263-3268. 
[107] Eder, G.; Smith, E. F.; Cebula, I.; Heckl, W. M.; Beton, P. H.; Lackinger, M. 2013, ACS Nano 7, 3014-3021.

[108] Batra, A.; Cvetko, D.; Kladnik, G.; Adak, O.; Cardoso, C.; Ferretti, A.; Prezzi, D.; Molinari, E.; Morgante, A.; Venkataraman, L. 2014, Chem. Sci. 5, 4419-4423.

[109] Cai, J.; Pignedoli, C. A.; Talirz, L.; Ruffieux, P.; Söde, H.; Liang, L.; Meunier, V.; Berger, R.; Li, R.; Feng, X.; et al. 2014, Nat. Nano. 9, 896-900.

[110] Cai, J.; Ruffieux, P.; Jaafar, R.; Bieri, M.; Braun, T.; Blankenburg, S.; Muoth, M.; Seitsonen, A. P.; Saleh, M.; Feng, X.; et al. 2010, Nature 466, 470-473.

[111] Basagni, A.; Sedona, F.; Pignedoli, C. A.; Cattelan, M.; Nicolas, L.; Casarin, M.; Sambi, M. 2015, J. Am. Chem. Soc. 137, 1802-1808.

[112] Ammon, M.; Sander, T.; Maier, S. 2017, J. Am. Chem. Soc. 139, 12976-12984.

[113] Han, P.; Akagi, K.; Federici Canova, F.; Mutoh, H.; Shiraki, S.; Iwaya, K.; Weiss, P. S.; Asao, N.; Hitosugi, T. 2014, ACS Nano 8, 9181-9187.

[114] Massimi, L.; Ourdjini, O.; Lafferentz, L.; Koch, M.; Grill, L.; Cavaliere, E.; Gavioli, L.; Cardoso, C.; Prezzi, D.; Molinari, E.; et al. 2015, J. Phys. Chem. C 119, 2427-2437.

[115] Blankenburg, S.; Cai, J.; Ruffieux, P.; Jaafar, R.; Passerone, D.; Feng, X.; Müllen, K.; Fasel, R.; Pignedoli, C. A. 2012, ACS Nano 6, 2020-2025.

[116] Otero, G.; Biddau, G.; Sanchez-Sanchez, C.; Caillard, R.; Lopez, M. F.; Rogero, C.; Palomares, F. J.; Cabello, N.; Basanta, M. A.; Ortega, J.; et al. 2008, Nature 454, 865-868.

[117] Treier, M.; Pignedoli, C. A.; Laino, T.; Rieger, R.; Mullen, K.; Passerone, D.; Fasel, R. 2010, Nat. Chem. 3.

[118] Wang, X.-Y.; Dienel, T.; Di Giovannantonio, M.; Barin, G. B.; Kharche, N.; Deniz, O.; Urgel, J. I.; Widmer, R.; Stolz, S.; De Lima, L. H.; et al. 2017, J. Am. Chem. Soc. 139, 4671-4674.

[119] In't Veld, M.; Iavicoli, P.; Haq, S.; Amabilino, D. B.; Raval, R. 2008, Chem. Commun. 1536-1538.

[120] Haq, S.; Hanke, F.; Sharp, J.; Persson, M.; Amabilino, D. B.; Raval, R. 2014, ACS Nano 8, 8856-8870.

[121] Zwaneveld, N. A. A.; Pawlak, R. m.; Abel, M.; Catalin, D.; Gigmes, D.; Bertin, D.; Porte, L. 2008, J. Am. Chem. Soc. 130, 6678-6679.

[122] Clair, S.; Ourdjini, O.; Abel, M.; Porte, L. 2011, Chem. Commun. 47, 8028-8030.

[123] Cui, D.; MacLeod, J. M.; Ebrahimi, M.; Perepichka, D. F.; Rosei, F. 2015, Chem. Commun. 51, 16510-16513.

[124] Dienstmaier, J. F.; Gigler, A. M.; Goetz, A. J.; Knochel, P.; Bein, T.; Lyapin, A.; Reichlmaier, S.; Heckl, W. M.; Lackinger, M. 2011, ACS Nano 5, 9737-9745.

[125] Dienstmaier, J. F.; Medina, D. D.; Dogru, M.; Knochel, P.; Bein, T.; Heckl, W. M.; Lackinger, M. 2012, ACS Nano 6, 7234-7242.

[126] Guan, C.-Z.; Wang, D.; Wan, L.-J. 2012, Chem. Commun. 48, 2943-2945.

[127] Plas, J.; Ivasenko, O.; Martsinovich, N.; Lackinger, M.; De Feyter, S. 2016, Chem. Commun. 52, 6871.

[128] Faury, T.; Clair, S.; Abel, M.; Dumur, F.; Gigmes, D.; Porte, L. 2012, J. Phys. Chem. C 116, 48194823.

[129] Greenwood, J.; Früchtl, H. A.; Baddeley, C. J. 2013, J. Phys. Chem. C 117, 4515-4520.

[130] Jensen, S.; Früchtl, H.; Baddeley, C. J. 2009, J. Am. Chem. Soc. 131, 16706-16713.

[131] Abel, M.; Clair, S.; Ourdjini, O.; Mossoyan, M.; Porte, L. 2011, J. Am. Chem. Soc. 133, 1203-1205.

[132] Weigelt, S.; Bombis, C.; Busse, C.; Knudsen, M. M.; Gothelf, K. V.; Lægsgaard, E.; Besenbacher, F.; Linderoth, T. R. 2008, ACS Nano 2, 651-660.

[133] Weigelt, S.; Busse, C.; Bombis, C.; Knudsen, M. M.; Gothelf, K. V.; Strunskus, T.; Wöll, C.; Dahlbom, M.; Hammer, B.; Lægsgaard, E.; et al. 2007, Angew. Chem. Int. Edit. 119, 9387-9390.

[134] Yegen, E.; Lippitz, A.; Treu, D.; Unger, W. E. S. 2008, Surf. Interface Anal. 40, 176-179.

[135] Ciesielski, A.; El Garah, M.; Haar, S.; Kovaříček, P.; Lehn, J.-M.; Samorì, P. 2014, Nat. Chem. 6, 1017-1023.

[136] Liu, X.-H.; Guan, C.-Z.; Zheng, Q.-N.; Wang, D.; Wan, L.-J. 2015, J. Chem. Phys. 142, 101905.

[137] Greenwood, J.; Baddeley, C. J. 2013, Langmuir 29, 653-657.

[138] Sun, X.-L.; Fan, L.-X.; Yang, Y.-J.; Guo, Z.; Tian, W. Q.; Lei, S. 2015, Chem. - Eur. J. 21, 68986905.

[139] Yu, Y.; Sun, J.; Lei, S. 2015, J. Phys. Chem. C 119, 16777-16784.

[140] Di Giovannantonio, M.; Kosmala, T.; Bonanni, B.; Serrano, G.; Zema, N.; Turchini, S.; Catone, D.; Wandelt, K.; Pasini, D.; Contini, G.; et al. 2015, J. Phys. Chem. C 119, 19228-19235. 
[141] Tanoue, R.; Higuchi, R.; Enoki, N.; Miyasato, Y.; Uemura, S.; Kimizuka, N.; Stieg, A. Z.; Gimzewski, J. K.; Kunitake, M. 2011, ACS Nano 5, 3923-3929.

[142] Tanoue, R.; Higuchi, R.; Ikebe, K.; Uemura, S.; Kimizuka, N.; Stieg, A. Z.; Gimzewski, J. K.; Kunitake, M. 2012, Langmuir 28, 13844-13851.

[143] Tanoue, R.; Higuchi, R.; Ikebe, K.; Uemura, S.; Kimizuka, N.; Stieg, A. Z.; Gimzewski, J. K.; Kunitake, M. 2014, J. Electroanal. Chem. 716, 145-149.

[144] Liu, X.-H.; Mo, Y.-P.; Yue, J.-Y.; Zheng, Q.-N.; Yan, H.-J.; Wang, D.; Wan, L.-J. 2014, Small 10, 4934-4939.

[145] Xu, L.; Zhou, X.; Yu, Y.; Tian, W. Q.; Ma, J.; Lei, S. 2013, ACS Nano 7, 8066-8073.

[146] Xu, L.; Zhou, X.; Tian, W. Q.; Gao, T.; Zhang, Y. F.; Lei, S.; Liu, Z. F. 2014, Angew. Chem. Int. Edit. 53, 9564-9568.

[147] Xu, L.; Cao, L.; Guo, Z.; Zha, Z.; Lei, S. 2015, Chem. Commun. 51, 8664-8667.

[148] Sun, X.; Fan, L.; Zhou, X.; Tian, W. Q.; Guo, Z.; Li, Z.; Li, X.; Lei, S. 2015, Chem. Commun. 51, 5864-5867.

[149] Yue, J.-Y.; Liu, X.-H.; Sun, B.; Wang, D. 2015, Chem. Commun. 51, 14318-14321.

[150] Liu, X.-H.; Wang, D.; Wan, L.-J. 2013, Chem. Asian J. 8, 2466-2470.

[151] Liu, X.-H.; Guan, C.-Z.; Ding, S.-Y.; Wang, W.; Yan, H.-J.; Wang, D.; Wan, L.-J. 2013, J. Am. Chem. Soc. 135, 10470-10474.

[152] Treier, M.; Richardson, N. V.; Fasel, R. 2008, J. Am. Chem. Soc. 130, 14054-14055.

[153] Eichhorn, J.; Heckl, W. M.; Lackinger, M. 2013, Chem. Commun. 49, 2900-2902.

[154] Gao, H.-Y.; Zhong, D.; Mönig, H.; Wagner, H.; Held, P.-A.; Timmer, A.; Studer, A.; Fuchs, H. 2014, J. Phys. Chem. C 118, 6272-6277.

[155] Gao, H.-Y.; Wagner, H.; Zhong, D.; Franke, J.-H.; Studer, A.; Fuchs, H. 2013, Angew. Chem. Int. Edit. 52, 4024-4028.

[156] Cirera, B.; Zhang, Y.-Q.; Björk, J.; Klyatskaya, S.; Chen, Z.; Ruben, M.; Barth, J. V.; Klappenberger, F. 2014, Nano Lett. 14, 1891-1897.

[157] Zhang, Y.-Q.; Kepčija, N.; Kleinschrodt, M.; Diller, K.; Fischer, S.; Papageorgiou, A. C.; Allegretti, F.; Björk, J.; Klyatskaya, S.; Klappenberger, F.; et al. 2012, Nat. Commun. 3, 1286.

[158] Gao, H.-Y.; Held, P. A.; Knor, M.; Mück-Lichtenfeld, C.; Neugebauer, J.; Studer, A.; Fuchs, H. 2014, J. Am. Chem. Soc. 136, 9658-9663.

[159] Matena, M.; Riehm, T.; Stöhr, M.; Jung, T. A.; Gade, L. H. 2008, Angew. Chem. Int. Edit. 120, 24482451.

[160] Okawa, Y.; Aono, M. 2001, Nature 409, 683-684.

[161] Okawa, Y.; Aono, M. 2002, Surf. Sci. 514, 41-47.

[162] Miura, A.; De Feyter, S.; Abdel-Mottaleb, M. M. S.; Gesquière, A.; Grim, P. C. M.; Moessner, G.; Sieffert, M.; Klapper, M.; Müllen, K.; De Schryver, F. C. 2003, Langmuir 19, 6474-6482.

[163] Grim, P. C. M.; De Feyter, S.; Gesquière, A.; Vanoppen, P.; Rüker, M.; Valiyaveettil, S.; Moessner, G.; Müllen, K.; De Schryver, F. C. 1997, Angew. Chem. Int. Edit. Engl. 36, 2601-2603.

[164] Sakaguchi, H.; Matsumura, H.; Gong, H.; Abouelwafa, A. M. 2005, Science 310, 1002-1006.

[165] Lapitan, L. D. S.; Tongol, B. J. V.; Yau, S.-L. 2010, Langmuir 26, 10771-10777.

[166] Chen, S.; Tu, H.; Wu, C.; Yau, S.; Fan, L.; Yang, Y. 2010, J. Phys. Chem. C 114, 8493-8499.

[167] Yau, S.; Lee, Y.; Chang, C.; Fan, L.; Yang, Y.; Dow, W.-P. 2009, J. Phys. Chem. C 113, 1375813764.

[168] Nakae, T.; Mizobuchi, S.; Yano, M.; Ukai, T.; Sato, H.; Shinmei, T.; Inoue, T.; Irifune, T.; Sakaguchi, H. 2012, Chem. Lett. 41, 140-141.

[169] Geng, Y.; Dai, H.; Chang, S.; Hu, F.; Zeng, Q.; Wang, C. 2015, ACS Appl. Mater. Interfaces 7, 46594666.

[170] de Oteyza, D. G.; Gorman, P.; Chen, Y.-C.; Wickenburg, S.; Riss, A.; Mowbray, D. J.; Etkin, G.; Pedramrazi, Z.; Tsai, H.-Z.; Rubio, A.; et al. 2013, Science 340, 1434-1437.

[171] Sun, Q.; Zhang, C.; Li, Z.; Kong, H.; Tan, Q.; Hu, A.; Xu, W. 2013, J. Am. Chem. Soc. 135, 84488451.

[172] Xi, M.; Bent, B. E. 1992, Surf. Sci. 278, 19-32.

[173] Paul, A.; Gellman, A. J. 1995, J. Am. Chem. Soc. 117, 9056-9066.

[174] Meyers, J. M.; Gellman, A. J. 1995, Surf. Sci. 337, 40-50.

[175] Hla, S.-W.; Bartels, L.; Meyer, G.; Rieder, K.-H. 2000, Phys Rev Lett 85, 2777-2780.

[176] Lewis, E. A.; Murphy, C. J.; Liriano, M. L.; Sykes, E. C. H. 2014, Chem. Commun. 50, 1006-1008. 
[177] Di Giovannantonio, M.; El Garah, M.; Lipton-Duffin, J.; Meunier, V.; Cardenas, L.; Fagot-Revurat, Y.; Cossaro, A.; Verdini, A.; Perepichka, D. F.; Rosei, F.; et al. 2014, ACS Nano 8, 1969-1971.

[178] Galeotti, G.; Di Giovannantonio, M.; Lipton-Duffin, J.; Ebrahimi, M.; Tebi, S.; Verdini, A.; Floreano, L.; Fagot-Revurat, Y.; Perepichka, D. F.; Rosei, F.; et al. 2017, Faraday Discuss. 204, 453-469.

[179] Talirz, L.; Ruffieux, P.; Fasel, R. 2016, Adv. Mater. 28, 6222-6231.

[180] Söde, H.; Talirz, L.; Gröning, O.; Pignedoli, C. A.; Berger, R.; Feng, X.; Müllen, K.; Fasel, R.; Ruffieux, P. 2015, Phys. Rev. B 91, 045429.

[181] Talirz, L.; Söde, H.; Cai, J.; Ruffieux, P.; Blankenburg, S.; Jafaar, R.; Berger, R.; Feng, X.; Müllen, K.; Passerone, D.; et al. 2013, J. Am. Chem. Soc. 135, 2060-2063.

[182] Ruffieux, P.; Cai, J.; Plumb, N. C.; Patthey, L.; Prezzi, D.; Ferretti, A.; Molinari, E.; Feng, X.; Müllen, K.; Pignedoli, C. A.; et al. 2012, ACS Nano 6, 6930-6935.

[183] Dienel, T.; Kawai, S.; Söde, H.; Feng, X.; Müllen, K.; Ruffieux, P.; Fasel, R.; Gröning, O. 2015, Nano Lett. 15, 5185-5190.

[184] Denk, R.; Hohage, M.; Zeppenfeld, P.; Cai, J.; Pignedoli, C. A.; Söde, H.; Fasel, R.; Feng, X.; Müllen, K.; Wang, S.; et al. 2014, Nat. Commun. 5.

[185] Russell, J. C.; Blunt, M. O.; Garfitt, J. M.; Scurr, D. J.; Alexander, M.; Champness, N. R.; Beton, P. H. 2011, J. Am. Chem. Soc. 133, 4220-4223.

[186] Wieland, M. B.; Slater, A. G.; Mangham, B.; Champness, N. R.; Beton, P. H. 2014, Beilstein J. Nanotechnol. 5, 394-401.

[187] Song, J.; Kam, F.-Y.; Png, R.-Q.; Seah, W.-L.; Zhuo, J.-M.; Lim, G.-K.; Ho, P. K. H.; Chua, L.-L. 2013, Nat. Nano. 8, 356-362.

[188] Llinas, J. P.; Fairbrother, A.; Borin Barin, G.; Shi, W.; Lee, K.; Wu, S.; Yong Choi, B.; Braganza, R.; Lear, J.; Kau, N.; et al. 2017, Nat. Commun. 8, 633.

[189] Vasseur, G.; Abadia, M.; Miccio, L. A.; Brede, J.; Garcia-Lekue, A.; de Oteyza, D. G.; Rogero, C.; Lobo-Checa, J.; Ortega, J. E. 2016, J. Am. Chem. Soc. 138, 5685-5692.

[190] Lehn, J.-M. 2002, Polym. Int. 51, 825-839.

[191] Skene, W. G.; Lehn, J.-M. P. 2004, Proc. Natl. Acad. Sci. U.S.A. 101, 8270-8275.

[192] Lehn, J.-M. 2005, Prog. Polym. Sci. 30, 814-831.

[193] Ono, T.; Nobori, T.; Lehn, J.-M. 2005, Chem. Commun. 1522-1524.

[194] Ono, T.; Fujii, S.; Nobori, T.; Lehn, J.-M. 2007, Chem. Commun. 4360-4362.

[195] Levrand, B.; Ruff, Y.; Lehn, J.-M.; Herrmann, A. 2006, Chem. Commun. 2965-2967.

[196] Ciesielski, A.; Lena, S.; Masiero, S.; Spada, G. P.; Samorì, P. 2010, Angew. Chem. Int. Edit. 49, 19631966.

[197] Ciesielski, A.; Schaeffer, G.; Petitjean, A.; Lehn, J.-M.; Samorì, P. 2009, Angew. Chem. 121, 20732077.

[198] Piot, L.; Meudtner, R. M.; El Malah, T.; Hecht, S.; Samorì, P. 2009, Chem. - Eur. J. 15, 4788-4792.

[199] Clair, S.; Abel, M.; Porte, L. 2014, Chem. Commun. 50, 9627-9635.

[200] Cordes, E. H.; Jencks, W. P. 1962, J. Am. Chem. Soc. 84, 832-837.

[201] Kovaříček, P.; Lehn, J.-M. 2012, J. Am. Chem. Soc. 134, 9446-9455.

[202] da Silva, C. M.; da Silva, D. L.; Modolo, L. V.; Alves, R. B.; de Resende, M. A.; Martins, C. V. B.; de Fátima, Â. 2011, J. Adv. Res. 2, 1-8.

[203] Belowich, M. E.; Stoddart, J. F. 2012, Chem. Soc. Rev. 41, 2003-2024.

[204] Zhang, T.; Zhou, W.; Jin, W.; Jin, Q.; Chen, H. 2013, Microchem. J. 108, 18-23.

[205] Cooper, A.; Dixon, S. F.; Nutley, M. A.; Robb, J. L. 1987, J. Am. Chem. Soc. 109, 7254-7263.

[206] Upthagrove, A. L.; Nelson, W. L. 2001, Drug Metab. Dispos. 29, 1114-1122.

[207] Björk, J.; Hanke, F.; Stafström, S. 2013, J. Am. Chem. Soc. 135, 5768-5775.

[208] Eichhorn, J.; Nieckarz, D.; Ochs, O.; Samanta, D.; Schmittel, M.; Szabelski, P. J.; Lackinger, M. 2014, ACS Nano 8, 7880-7889. 